\title{
OPEN Genetic origins and diversity of bushpigs from Madagascar (Potamochoerus larvatus, family Suidae)
}

\author{
Carol Lee ${ }^{1}$, Jenna Day ${ }^{1}$, Steven M. Goodman ${ }^{2,3}$, Miguel Pedrono ${ }^{4}$, Guillaume Besnard ${ }^{5}$ \\ Laurent Frantz ${ }^{6,7}$, Peter J. Taylor ${ }^{8,9}$, Michael J. Herrera ${ }^{10}$ \& Jaime Gongora ${ }^{1 凶}$
}

The island of Madagascar, situated off the southeast coast of Africa, shows the first evidence of human presence $~ 10,000$ years ago; however, other archaeological data indicates a settlement of the modern peoples of the island distinctly more recent, perhaps $>1500$ years ago. Bushpigs of the genus Potamochoerus (family Suidae), are today widely distributed in Madagascar and presumed to have been introduced from Africa at some stage by human immigrants to the island. However, disparities about their origins in Madagascar have been presented in the literature, including the possibility of endemic subspecies, and few empirical data are available. Furthermore, the separation of bushpigs in Madagascar from their mainland relatives may have favoured the evolution of a different repertoire of immune genes first due to a founder effect and then as a response to distinct pathogens compared to their ancestors. Molecular analysis confirmed the species status of the bushpig in Madagascar as $P$. larvatus, likely introduced from the central region of southern Africa, with no genetic evidence for the recognition of eastern and western subspecies as suggested from previous cranial morphology examination. Investigation of the immunologically important SLA-DQB1 peptide-binding region showed a different immune repertoire of bushpigs in Madagascar compared to those on the African mainland, with seventeen exon-2 haplotypes unique to bushpigs in Madagascar (2/28 haplotypes shared). This suggests that the MHC diversity of the Madagascar populations may have enabled Malagasy bushpigs to adapt to new environments.

The first evidence of human presence in Madagascar, situated off the south-eastern coast of Africa, dates from close to 10,000 years ago ${ }^{1}$. Subsequently, the island was settled by Austronesians approximately 1500-3000 years ago and then soon thereafter by Bantu groups from East Africa, but evidence of this remains unclear ${ }^{2-4}$. The bushpig (Potamochoerus larvatus; Suidae, Artiodactyla) is suggested to have been introduced to Madagascar from eastern Africa by early sea navigators who settled on the island $d^{5,6}$. The earliest archaeological evidence for the bushpig on Madagascar dates to the tenth to thirteenth centuries ${ }^{7}$. On other regional islands, archaeological records show evidence of bushpigs on the Comoro Islands from the ninth to tenth centuries ${ }^{8,9}$. However, there are large gaps in the paleontological record of Madagascar between the Late Cretaceous and the Late Pleistocene $(\sim 66 \text { million to } 120,000 \text { years ago })^{10}$, as well as the Holocene (the earliest possible Potamochoerus introduction to Madagascar), hampering the determination of when and where the species was first established on the island and whether this predates human arrival. Genetic evidence is useful to assess where the Potamochoerus lineage(s) on the island originated from and determine whether their separation resulted in any significant

\footnotetext{
${ }^{1}$ Sydney School of Veterinary Science, Faculty of Science, The University of Sydney, Sydney, NSW 2006, Australia. ${ }^{2}$ Field Museum of Natural History, Chicago, IL 60605, USA. ${ }^{3}$ Association Vahatra, 101 Antananarivo, Madagascar. "UMR ASTRE, INRAE, CIRAD, Université de Montpellier, 34398 Montpellier Cedex 5, France. ${ }^{5}$ CNRS, UPS, IRD, Laboratoire Evolution et Diversité Biologique, UMR5174, Université Toulouse III Paul Sabatier, 31062 Toulouse, France. ${ }^{6}$ Palaeogenomics Group, Department of Veterinary Sciences, Ludwig Maximilian University, Munich, Germany. ${ }^{7}$ School of Biological and Chemical Sciences, Queen Mary University of London, London, UK. ${ }^{8}$ School of Mathematical and Natural Sciences, University of Venda, Thohoyandou, Limpopo Province, South Africa. ${ }^{9}$ Afromontane Research Unit and Zoology Department, University of the Free State, Qwa Qwa campus, Phuthaditjhaba 9866, South Africa. ${ }^{10}$ Archaeological Studies Program, University of the Philippines Diliman, 1101 Quezon City, Philippines. ${ }^{\boxplus}$ email: jaime.gongora@sydney.edu.au
} 


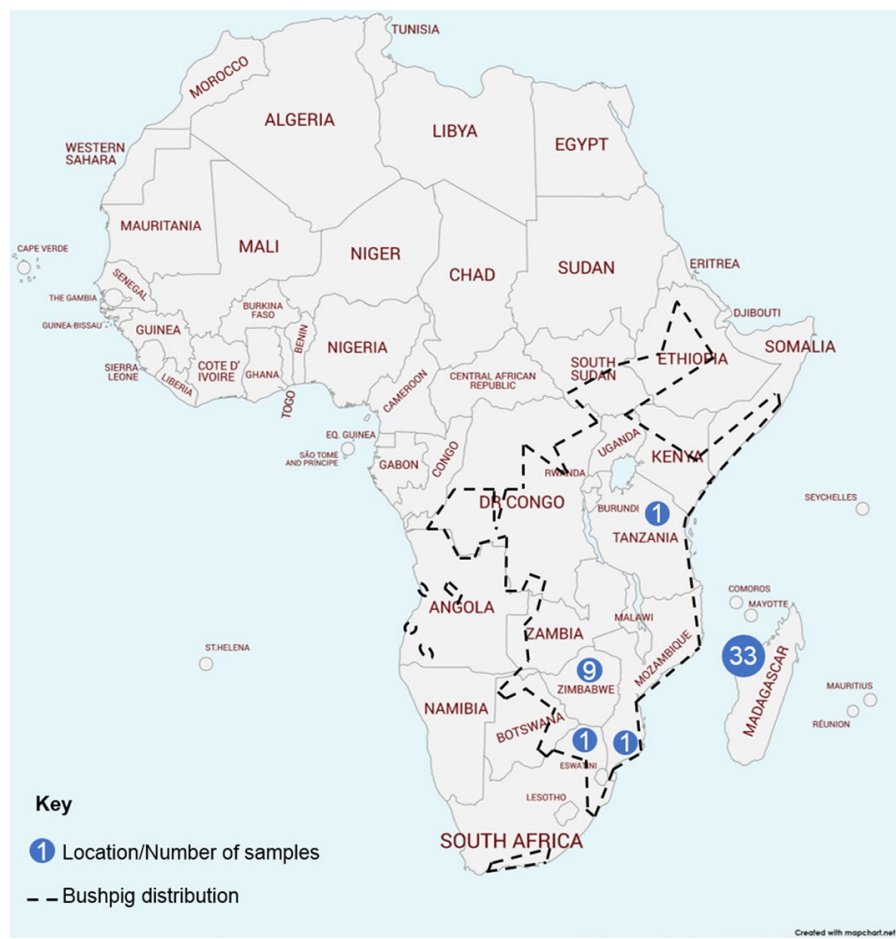

Figure 1. Map of native bushpig distribution as illustrated in the IUCN. Map is a modified version by mapchart.net.

genetic differentiation from their mainland counterparts, in particular, genomic regions that underlie the adaptive immune response to diseases and other environmental challenges ${ }^{11,12}$. Bushpigs are classified as Least Concerned on the IUCN Red List ${ }^{13}$ and a pest as they damage farmlands and prey on endemic Malagasy species ${ }^{14}$. However, they are an important meat source and income for some rural populations in Madagascar, and seed dispersers of some native flora ${ }^{14}$. Understanding their genetic diversity is essential for sustainable population management, protecting local agriculture, and the health of the local ecosystem.

The genus Potamochoerus includes two separate species: P. larvatus distributed in portions of eastern, central, and southern Africa (Fig. 1) and P. porcus occurring in the Congo Basin and western Africa. Based on few specimens and mostly cranio-dental characteristics, early taxonomists proposed that the western and eastern populations of bushpigs in Madagascar should be separated into two endemic subspecies, $P$. l. larvatus from the West and $P$. l. hova from the East ${ }^{15}$. However, other taxonomists have concluded that bushpigs from Madagascar are morphologically indistinguishable from African specimens of $P$. larvatus ${ }^{16}$, in which provisional subspecies separating bushpigs from eastern Africa and those from southern African and Madagascar, are distinguished based on cranial differences and body colour ${ }^{15}$. Due to the considerable phenotypic variation in mainland African Potamochoerus, both within and between populations, the origins of animals in Madagascar have been difficult to discern based on cranio-dental characters. Although it has been proposed that the eastern bushpigs of Madagascar may have originated from southern African populations based on similarities to P. l. koiropotamus (ranging from Tanzania, to northern South Africa) ${ }^{15,17}$, western bushpigs of Madagascar are apparently more similar to those found on the Comoro Islands, which are also presumably introduced, and appear larger than their eastern and mainland equivalents ${ }^{15,18,19}$. For Madagascar, it is possible that bushpigs were introduced to the island prior to the ninth century AD and the gradual spread of Islam in East Africa may have increased the translocation of bushpigs to offshore islands by hunter-gathers of other communities ${ }^{8,20}$. This could have occurred via the Comoros, perhaps using the Southern Equatorial which connects the southeast trade winds, as (limited) evidence of Potamochoerus has been found at M'Bachile on Grande Comore dating to the ninth-tenth century 9 . Although the North Mozambique current may have been used, this route is more treacherous for sailing vessels due to the reefs and sandbars along this current ${ }^{21}$.

Wild suids in Africa-Phacochoerus and Potamochoerus spp.-have important ecological implications as hosts or reservoirs in a range of diseases such as African swine fever virus (ASFV) ${ }^{22-25}$. ASFV can devastate domestic pig populations and cause huge economic loss for farmers ${ }^{26,27}$. Bushpigs can be asymptomatically infected by ASFV but previous studies have indicated that bushpigs in Madagascar have an insignificant role in ASFV transmission due to the absence of circulating ASFV, anti-ASFV antibodies, nor antibodies to tick vectors (Ornithodoros spp. $)^{11}$. The separation of Malagasy bushpigs from the mainland has raised questions about the change in their susceptibility to ASFV due to genetic drift and an absence of natural infection. In general, the introduction of few founders on islands often have adverse effects on fitness of subsequently established populations ${ }^{12,28}$. This is of particular interest as the relevant antibodies were detected in domestic pigs from shared habitats and occasional contacts between these two groups and arthropods in the environment could play 


\begin{tabular}{|c|c|c|c|c|}
\hline Species name & Common name & $N$ & Distribution & Sampling location \\
\hline \multirow{4}{*}{ Potamochoerus larvatus } & Bushpig & $18^{\mathrm{a}}$ & Sub-Saharan Africa (mainland) & $\begin{array}{l}\text { Tervuren (Belgium), Duisburg Zoo (Germany), Soutpansberg (South Africa), Zim- } \\
\text { babwe, KwaZulu-Natal (South Africa), Tanzania }\end{array}$ \\
\hline & Bushpig & $38^{\mathrm{a}}$ & Madagascar & "West" Madagascar \\
\hline & Bushpig & 4 & Madagascar & "East" Madagascar \\
\hline & Bushpig & 1 & Madagascar & "North" Madagascar \\
\hline Potamochoerus porcus & Red river hog & 3 & Sub-Saharan Africa & Tervuren (Belgium), Rotterdam Zoo (Netherlands), Duisburg Zoo (Germany) \\
\hline Phacochoerus africanus & Common warthog & 1 & Sub-Saharan Africa & Iwaba (Zimbabwe) \\
\hline Hylochoerus meinertzhageni & Forest hog & 1 & Sub-Saharan Africa & Uganda \\
\hline Sus scrofa & Wild boar & 1 & Eurasia & Yorkshire Farm (UK) \\
\hline Sus barbatus & Bornean bearded pig & 1 & Southeast Asia & ZSL Animal Hospital (UK) \\
\hline Sus celebensis & Sulawesi warty pig & 1 & Southeast Asia & Sulawesi mainland (Indonesia) \\
\hline Babyrousa babyrussa & Babirusa & 1 & Southeast Asia & Edinburgh Zoo (UK) \\
\hline Pecari tajacu & Collared peccary & $20^{\mathrm{a}}$ & South America & Macagual and Barranquilla Zoo (Colombia) \\
\hline
\end{tabular}

Table 1. Details of pig and peccary samples used in this study. The species common name, natural distribution, sampling location and number of samples $(N)$ are indicated. ${ }^{\text {a }}$. larvatus samples included replicates for six individuals and $P$. tajacu included replicates for three individuals (one individual replicated twice).

a role in maintaining ASFV in Madagascar ${ }^{11,23}$. The major histocompatibility complex (MHC) is an important part of adaptive and innate immunity in vertebrates ${ }^{29}$ and has been studied comprehensively in model species including the domestic pig (Sus scrofa) and humans ${ }^{30-33}$. Genetic diversity in this genomic region contributes to individual and population fitness in natural populations through pathogen recognition ${ }^{12,34}$. In particular, the antigen-binding sites (ABS) within the class I and class II MHC molecules are responsible for self and non-self recognition and present peptides to the CD4+ T lymphocytes for surveillance ${ }^{35,36}$. The high genetic diversity in the MHC can be caused by different evolutionary mechanisms such as gene duplication and pathogen-mediated co-evolution and consequently diversification of the ABS through balancing and positive selection for advantageous alleles ${ }^{37-39}$. Balancing selection has been described as one of the major factors driving this diversity as a higher number of different alleles (heterozygote advantage) could bind and present different antigens ${ }^{40,41}$. Thus, examining the MHC of bushpigs from Madagascar could provide an opportunity to better understand how these mechanisms have changed the MHC repertoire of Potamochoerus over space and time.

In this study, the origins and taxonomic position of bushpigs from Madagascar were assessed using the Sanger sequencing data of mitochondrial (control region; CR, and cytochrome $b$; cytb) and nuclear markers (glucosephosphate isomerase-processed pseudogene; GPIP, and melanocortin 1 receptor; MC1R). A range of suids and peccaries (nine species), and specimens of Potamochoerus from Madagascar were sequenced in this study. Due to the varied bioclimatic regime found in different areas of the island ${ }^{42}$, as compared to mainland Africa, we sequenced three MHC loci to assess whether the separation of Malagasy bushpigs generated a different repertoire of immune genes compared to mainland bushpigs. These genetic analyses provide insights into the diversity of the Malagasy bushpig adaptive immune system in comparison to mainland bushpigs since their separation. Similar comparisons could be used to assess the fitness and historical changes incurred by other species translocated to Madagascar.

\section{Materials and methods}

Sampling. Genomic DNA was extracted from blood and tissue samples from a total of 80 individuals (Table 1). Samples included 55 bushpigs (P. larvatus) consisting of 13 specimens from mainland Africa (Zimbabwe, Tanzania-museum specimen, South Africa; SA), and 42 specimens from regions of "West" Madagascar (general Mahajanga Province area, which includes a museum specimen collected near the Ambohijanahary Special Reserve and two other protected areas: the Menabe Antimena and the Ankarafantsika National Park), "East" Madagascar (Andasibe-Mantadia protected area), and "North" Madagascar (museum specimen collected from Forêt d'Antsahabe, Antsiranana Province) (Fig. 1). Genomic DNA for non-museum specimens and museum specimens were extracted using the DNeasy Blood \& Tissue Kit (Qiagen, France) and phenol/chloroform method, respectively. Museum specimens were provided by the Field Museum of Natural History, Illinois, USA. Samples were collected under permission from the Direction Générale des Eaux et Forêts de Madagascar (Supplementary Table S1). The tissue samples were from recently killed bushpigs found during field trips and skulls were kept as voucher specimens. Although Madagascar no longer uses the province system in an administrative manner, we maintain these names for geographical descriptive purposes. For phylogenetic comparison and to provide an overview on the similarity of immune genes, the study also included sampling of three red river hogs (P. porcus), 16 collared peccaries (Pecari tajacu), and one specimen of the following species: European wild boar (S. scrofa), Bornean beared pig (S. barbatus), Celebes warty pig (S. celebensis), Buru babirusa (Babyrousa babyrussa), common warthog (Phacochoerus africanus), and giant forest hog (Hylochoerus meinertzhageni) (Table 1). Outgroup species were obtained from previous studies ${ }^{43-45}$. 


\begin{tabular}{|c|c|c|c|c|c|}
\hline Genomic region & Locus & Primer name & Primer sequence $\left(5^{\prime} \rightarrow 3^{\prime}\right)$ & Target size (bp) & Source \\
\hline \multirow{2}{*}{ mtDNA } & CR & $\begin{array}{l}\text { CR L } \\
\text { CR H }\end{array}$ & $\begin{array}{l}\text { CCAAGACTCAAGGAA } \\
\text { GGAGA } \\
\text { GGCGCGGATACTTGC } \\
\text { ATGTG }\end{array}$ & 1036 & 46 \\
\hline & $c y t b$ & LT4724 H15915R & $\begin{array}{l}\text { CGAAGCTTGATATGA } \\
\text { AAAACCATGGTTG } \\
\text { GGAATTCATCTCTCC } \\
\text { GGTTTACAAGAC } \\
\end{array}$ & 1140 & 47 \\
\hline \multirow{5}{*}{ nuDNA } & GPIP & $\begin{array}{l}\text { GPIP1 } \\
\text { GPIP6 }\end{array}$ & $\begin{array}{l}\text { TGCAGTTGAGAAGGA } \\
\text { CTTTACTT } \\
\text { GAAGTTACAGGGCAT } \\
\text { CATCTTG }\end{array}$ & 507 & 48,49 \\
\hline & $M C 1 R$ & $\begin{array}{l}\text { MC1R-F } \\
\text { MC1R-R }\end{array}$ & $\begin{array}{l}\text { AGTGCCTGGAGGTGT } \\
\text { CCATTCAC } \\
\text { CGTAGATGAGGGGGT } \\
\text { CCAGGATAGA }\end{array}$ & 795 & 50 \\
\hline & SLA-6 (class I) & $\begin{array}{l}\text { SLA-6F } \\
\text { SLA-6R }\end{array}$ & $\begin{array}{l}\text { TCAGCCYCTCCCTGTT- } \\
\text { MTAG } \\
\text { GTTCCTGCACCCCCT- } \\
\text { TASAC }\end{array}$ & 314 & Lee et al., unpublished \\
\hline & $S L A-D Q B 1$ (class II) & $\begin{array}{l}\text { DQB1-e2_F } \\
\text { DQB1-e2_R }\end{array}$ & $\begin{array}{l}\text { GCCTGACTGACGCGG } \\
\text { TATCTC } \\
\text { GAGTGCCTGCCCGCC }\end{array}$ & 315 & Lee et al., unpublished \\
\hline & BAG6 (class III) & $\begin{array}{l}\text { BAG6-F } \\
\text { BAG6-R }\end{array}$ & $\begin{array}{l}\text { CCCTTGCTCCСTCTT } \\
\text { CTACC } \\
\text { GCTTCTCATGCAGCC } \\
\text { TGTG }\end{array}$ & 895 & This study \\
\hline
\end{tabular}

Table 2. Oligonucleotide primers used to amplify and sequence mitochondrial (mtDNA) and nuclear DNA sequences (nuDNA).

Selection of target regions. To examine the phylogenetic position of bushpigs from Madagascar, the mitochondrial $\mathrm{CR}^{46}$ and $c y t b^{47}$, and the nuclear GPIP region ${ }^{48,49}$ and $M C 1 R^{50}$ region were sequenced. Mitochondrial markers have been extensively used to infer evolutionary relationships of many organisms ${ }^{51-54}$. The control region and cytochrome $b$ has been particularly valuable in Suidae and Tayassuidae; identifying differences amongst species and pig breeds ${ }^{48,55-57}$. The mitochondrial markers were concatenated as they are essentially a single, non-recombining locus. The nuclear marker GPIP was sequenced due to minimal selection pressures and previous studies have shown the ability of this marker to differentiate between $S$. scrofa clades ${ }^{55,58}$ but has not been used in the context of wild suid populations. The nuclear marker $M C 1 R$ plays a key role in regulating eumelanin (black/brown) and phaemelanin (red/yellow) and is responsible for coat, hair, and skin colour variation in various pig breeds ${ }^{48,59}$ and may be useful in distinguishing the presence of population differences based on coat colour. Partial genes from each of the MHC class I, II and III were also sequenced to assess the immunogenetic diversity of bushpigs from Madagascar. The MHC class I classical genes were not targeted due to their high level of gene duplication which can reduce the resolution of analyses. Instead, the MHC class I nonclassical SLA-6 exon-2 region was targeted (alpha-1), as well as SLA-DQB1 exon-2 (class II), and region spanning residues 450-518 (exons 11-14) of the class III BAG6 gene, which has been suggested to be associated with ASFV infection in the host ${ }^{60,61}$. Primers used for sequencing the MHC class I and II genes were designed based on the S. scrofa haplotype Hpla. $1^{31,62,63}$ and primers class III BAG6 were designed by the Australian Genome Research Facility (AGRF) Ltd, Australia, based on the Sscrofa11.1 reference genome (Gene ID: 100153950) (Table 2). PCR and sequencing were performed at AGRF Ltd, Australia. The raw forward and reverse chromatograms were assessed, and sequences manually edited using SeqTrace ${ }^{64}$. Sequences were then assembled to give a consensus sequence for each sample (excluding primer sequences).

Datasets used for downstream analyses. The number and assignment of haplotypes for CR, cytb, GPIP and MC1R were determined using DnaSP $6^{65}$. To determine the phylogenetic position of bushpigs from Madagascar in relation to other members of the family Suidae, we also included available sequences of the CR, $c y t b, G P I P$, and MC1R from NCBI (https://www.ncbi.nlm.nih.gov/) for wild species of pigs and peccaries (Supplementary Table S2) ${ }^{48,66-73}$. The following Datasets were prepared for downstream analyses (Table 3). Dataset (1a) includes concatenation of both mitochondrial sequences (CR, cytb) from this study and available NCBI data; (1b) includes either mtDNA sequences available for each species/sample; (2) sequenced and available NCBI GPIP region; (3) sequenced and available NCBI MC1R region; (4) SLA-6; (5) SLA-DQB;1 and (6) BAG6 sequences from this study. For Datasets $1 \mathrm{a}$ and $1 \mathrm{~b}$, sequences were aligned in ClustalW ${ }^{74}$ and concatenated in SequenceMatrix ${ }^{75}$ to produce one sequence for each representative species. Concatenated sequences are useful to overcome sampling error and missing data, and can show accuracy in generating taxonomic topologies ${ }^{76-78}$.

Inferring the relationship of bushpigs in Madagascar. Phylogenetic inferences were generated based on Datasets 1-3 (Table 3) using the RAxML-NG v0.09.0 web-based server ${ }^{79}$. The partitions to accommodate for different evolutionary models were based on the Bayesian Information Criterion ${ }^{80}$ identified by 


\begin{tabular}{|c|c|c|c|c|c|c|}
\hline \multirow[b]{2}{*}{ Dataset no } & \multirow[b]{2}{*}{ Gene } & \multicolumn{2}{|c|}{ Number of sequences } & \multirow[b]{2}{*}{ Partition/model } & \multirow[b]{2}{*}{ Aligned length (bp) } & \multirow[b]{2}{*}{$\begin{array}{l}\text { Concatenated length } \\
\text { (bp) }\end{array}$} \\
\hline & & Bushpigs & $\begin{array}{l}\text { Other suids and } \\
\text { tayassuids }\end{array}$ & & & \\
\hline \multirow{2}{*}{ 1a } & $\mathrm{CR}$ & $98(1)$ & $12(20)$ & $\mathrm{HKY}+\mathrm{I}+\mathrm{G}$ & 1451 & \multirow{2}{*}{2592} \\
\hline & cytb & $110(1)$ & $14(17)$ & $\mathrm{HKY}+\mathrm{G}$ & 1141 & \\
\hline \multirow{2}{*}{$1 \mathrm{~b}$} & CR & \multirow{2}{*}{$110(1)$} & \multirow{2}{*}{$16(20)$} & $\mathrm{HKY}+\mathrm{I}+\mathrm{G}$ & 1451 & \multirow{2}{*}{2592} \\
\hline & $c y t b$ & & & $\mathrm{HKY}+\mathrm{G}$ & 1141 & \\
\hline 2 & GPIP & $102(1)$ & $14(11)$ & $\mathrm{K} 80+\mathrm{I}$ & 462 & \\
\hline 3 & $M C 1 R$ & $100(0)$ & $14(4)$ & $\mathrm{HKY}+\mathrm{I}$ & 787 & \\
\hline 4 & SLA-6 & 104 & 16 & K2 & 270 & \\
\hline 5 & SLA-DQB1 & 94 & 16 & T92 & 270 & \\
\hline 6 & BAG6 & 96 & 34 & JC & 433 & \\
\hline
\end{tabular}

Table 3. Datasets used for phylogenetic and/or haplotype analyses. The gene, number of sequences, aligned length, and concatenated length of each dataset are indicated. The partition and model for phylogenetic and genetic diversity analyses are indicated for the respective genes. Numbers in brackets indicate the number of NCBI sequences used. Accession numbers are provided in Supplementary Table S2.

ModelGenerator ${ }^{81}$ and listed for each gene in Table 3. PopArt v1. $7^{82}$ was used to produce Medium-Joining Networks (MJN) of only bushpig sequences to visualise the intra-relationships of mainland and Madagascar samples of different loci in this study (Datasets 1-6).

Analyses of MHC genetic diversity and selection. To observe whether the MHC sequence of bushpigs from Madagascar has been subjected to purifying or diversifying selection since their introduction to the island, we performed selection analysis using DataMonkey ${ }^{83}$. We estimated selection based on (1) all haplotypes identified, (2) bushpigs from Madagascar only, and (3) mainland bushpigs-selection for SLA-6 was based on all haplotypes only as three or more input sequences in DataMonkey is required. Selection tests can be used for identifying certain positions in genes or regions (particularly in coding regions) that are conserved or have underwent radical changes in some taxa, and for testing an increase of nonsynonymous substitutions than expected under neutral evolution ${ }^{84}$. Diversifying selection is observed by a higher nonsynonymous substitution rate $(\mathrm{dN})$ compared to the synonymous substitution rate $(\mathrm{dS})$. A $\mathrm{dN} / \mathrm{dS}$ ratio $>1$ suggests the presence of positive or diversifying selection; $\mathrm{dN} / \mathrm{dS}<1$ indicates negative or purifying selection; and $\mathrm{dN} / \mathrm{dS} \sim 1$ indicates no selection. We tested four different methods for detecting sites under selection: MEME (Mixed Effects Model of Evolution), FEL (Fixed Effects Likelihood), SLAC (Single-Likelihood Ancestor Counting), and REL (Random Effects Likelihood). For each method, the significant levels were the following: $P \leq 0.05$ in $\mathrm{MEME}^{85}, P \leq 0.25$ in FEL and SLAC, and a Bayes Factor of $>50$ in $\mathrm{REL}^{86}$. Only sites significantly identified under positive selection by at least two methods were considered ${ }^{87,88}$.

Genetic diversity was calculated in MEGA $7^{89}$ using the model-of-best-fit Tamura 92 (T92) ${ }^{90}$, Kimura-2 parameter $(\mathrm{K} 2)^{91}$, and Jukes-Cantor $(\mathrm{KC})^{92}$ for $S L A-D Q B 1, S L A-6$, and BAG6, respectively. Standard error was calculated using 1,000 bootstraps. Based on initial genetic diversity analysis, genetic distance was also calculated for $S L A-D Q B 1$ in MEGA 7 using p-distance in coding positions only and sites with $<95 \%$ coverage were discarded from analysis.

Divergence of bushpigs from mainland Africa and Madagascar. BEAST v2.4. $8^{93}$ was used to estimate the divergence time between bushpigs in mainland Africa and Madagascar. Concatenated mitochondrial $\mathrm{CR}$ and $c y t b$ sequence alignments were subsampled to include members of Potamochoerini, Phacochoerini, and Suini, a Babyrousa, and a Pecari as an outgroup (Dataset 1a; Table 3; Supplementary Table S1). Independent test runs using the $M C 1 R$ and GPIP nuclear genes were also performed and evaluated. The sequences were aligned using ClustalW algorithm in Geneious v.11.0.4 (https://www.geneious.com) ${ }^{94}$. PartitionFinder2 on XSEDE ${ }^{95}$ was used to determine the best substitution model and best partitioning scheme for the dataset. It provided four data blocks including the CR, and the first, second, and third codon of the cytb gene (Supplementary Table S3). The best partitioning scheme and substitution model as indicated by PartitionFinder were used in the downstream BEAST analysis. BEAST was implemented using a calibrated Yule tree prior and a single uncorrelated relaxed lognormal clock model. The molecular clock was calibrated by constraining the time to most recent common ancestor (TMRCA) of the Suoidea (Tayassuidae-Suidae split) according to normal distribution prior with a mean of 37.09 Mya and a sigma of 0.5. The Suiodea TMRCA prior around of 34.50-39.69 Mya was previously estimated and is in consensus with other estimated molecular and fossil analyses ${ }^{67}$. The BEAST MCMC chain was set to run for 20 million generations (replicated three times) with the first $10 \%$ set as burn-in. The models and parameters for the BEAST run were prepared using BEAUTi ${ }^{96}$. The BEAST analysis was independently replicated three times using a different starting seed each time. All the generated log and tree files were combined using LogCombiner ${ }^{97}$. The BEAST analysis was evaluated using Tracer v1.7.1 ${ }^{98}$ by ensuring an effective sample size (ESS) of $>200$ and convergence. TreeAnnotator ${ }^{97}$ was used to summarize the tree topologies, generate the best supported BEAST trees (maximum clade credibility tree) corresponding to the 95\% HPD ranges, and to estimate the posterior clade probability of each node. FigTree v.1.4.3 (https://tree.bio.ed.ac.uk/software/figtr $\mathrm{ee} /)^{99}$ was used to visualize and evaluate the estimated tree. 


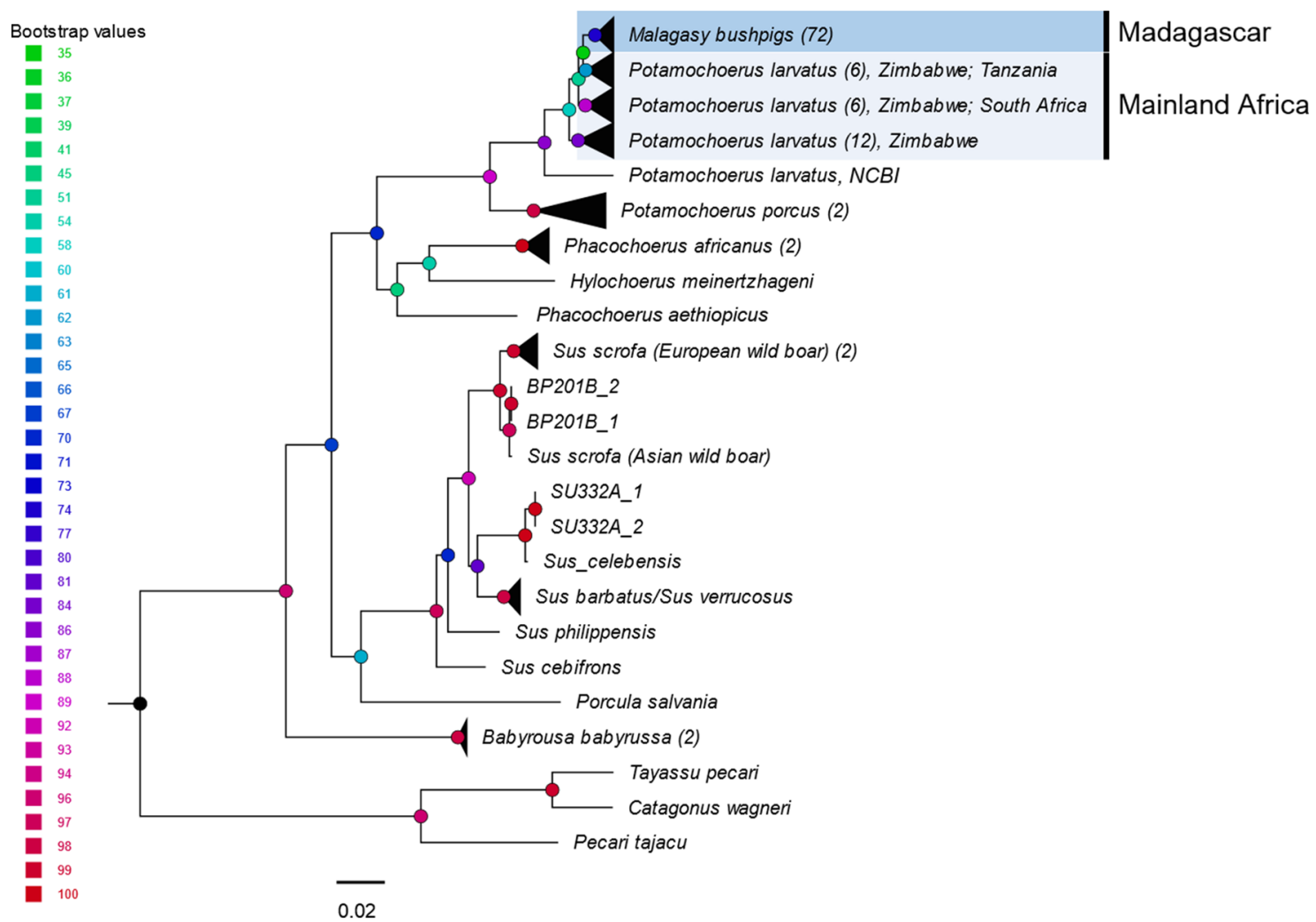

Figure 2. Phylogenetic tree indicating the position of Malagasy bushpigs as Potamochoerus larvatus. A Maximum Likelihood tree was generated, based on concatenated mtDNA (CR and Cytb) and nuDNA (GPIP and $M C 1 R$ ) sequences, using the RAxML-NG v0.6.0 web-server ${ }^{79}$ (https://raxml-ng.vital-it.ch/\#/). Statistical support was assessed using a bootstrap cut-off of 0.03 (Bootstrap support indicated above the branches). Numbers in brackets indicate the number of sequences from this study within each node.

Ethics approval and consent to participate. Bushpig samples were collected under permission from the Direction Générale des Eaux et Forêts de Madagascar or were collected from hunters, and museum specimens were provided by the Field Museum of Natural History, Illinois, USA. Other species were sourced from previous studies ${ }^{31,62,63}$.

\section{Results}

Phylogenetic relationship and divergence of bushpigs from Madagascar to other Suidae. Phylogenetic analysis of concatenated mtDNA (Dataset 1a; Fig. 2) and non-concatenated mtDNA genes (Datasets 2-3; Supplementary Fig. S1 and Fig. S2) using the maximum likelihood method showed that specimens of bushpigs from Madagascar and mainland bushpigs formed a monophyletic clade. Bushpigs from "East", "West" or "North" Madagascar, did not form reciprocal monophylogetic lineages. Furthermore, some mainland bushpigs, including those from Zimbabwe $(n=3)$ and Tanzania $(n=1)$ appear as a sister clade to Madagascar bushpigs. This is followed by those from South Africa $(n=2)$, and the remaining specimens from Zimbabwe $(n=6)$. Trees inferred from Dataset 1b (Supplementary Fig. S3) was consistent to Dataset 1a. The topology for nuclear DNA markers was less resolved. Both GPIP and MC1R showed little resolution of bushpig samples but were sufficient to cluster other extant suids separately from bushpigs (Supplementary Fig. S3 and Fig. S4). Surprisingly, one bushpig sample obtained from Tervuren (Belgium) clustered with S. scrofa samples for each analysis; presumably due to sampling error/mislabelling. The specimens of bushpigs from Madagascar employed herein are genetically distinct, even in the highly conserved GPIP and MC1R genes, from the P. porcus specimens available for this study. The $56 \mathrm{CR}, 62 c y t b, 52 \mathrm{GPIP}$, and $51 \mathrm{MC} 1 \mathrm{R}$ have been submitted to GenBank under accession numbers: MT853484-MT853538, MT864081-MT864142, MT864030-MT864080, and MT864143-MT864192.

Based on the concatenated mitochondrial DNA dataset, the BEAST analysis places the node age estimates for the divergence of Malagasy bushpigs and mainland African bushpigs at $0.49 \mathrm{MA}$ (node A; 95\% Higher Posterior Density [HPD] 0.27-0.77 Ma). The Bayesian Posterior Probability (BPP) score for this node was 0.73 . Time divergence for the split between other mainland African bushpigs (nodes B and C) was estimated to be between 0.41 and $0.76 \mathrm{Ma}(\mathrm{BPP}=1)$ and the split from . porcus estimated at 1.81-4.34 Ma (node D). The TMRCA of the Suidae group was 7.74 Ma (95\% HPD 5.42-10.44 Mya; BPP =0.82), while the split between Suinae and Babyrousinae is at 9.27 Mya (95\% HPD 5.94-12.68; BPP =0.99). None of the nodes got a BPP score of $<0.5$.

We did not estimate divergence time between Madagascan and mainland African bushpigs using the nuclear gene $M C 1 R$ and pseudogene GPIP as test runs produced very unresolved trees. In addition, previous work did not include the $M C 1 R$ gene for divergence time estimation due to strong phenotypic selection ${ }^{48}$. 


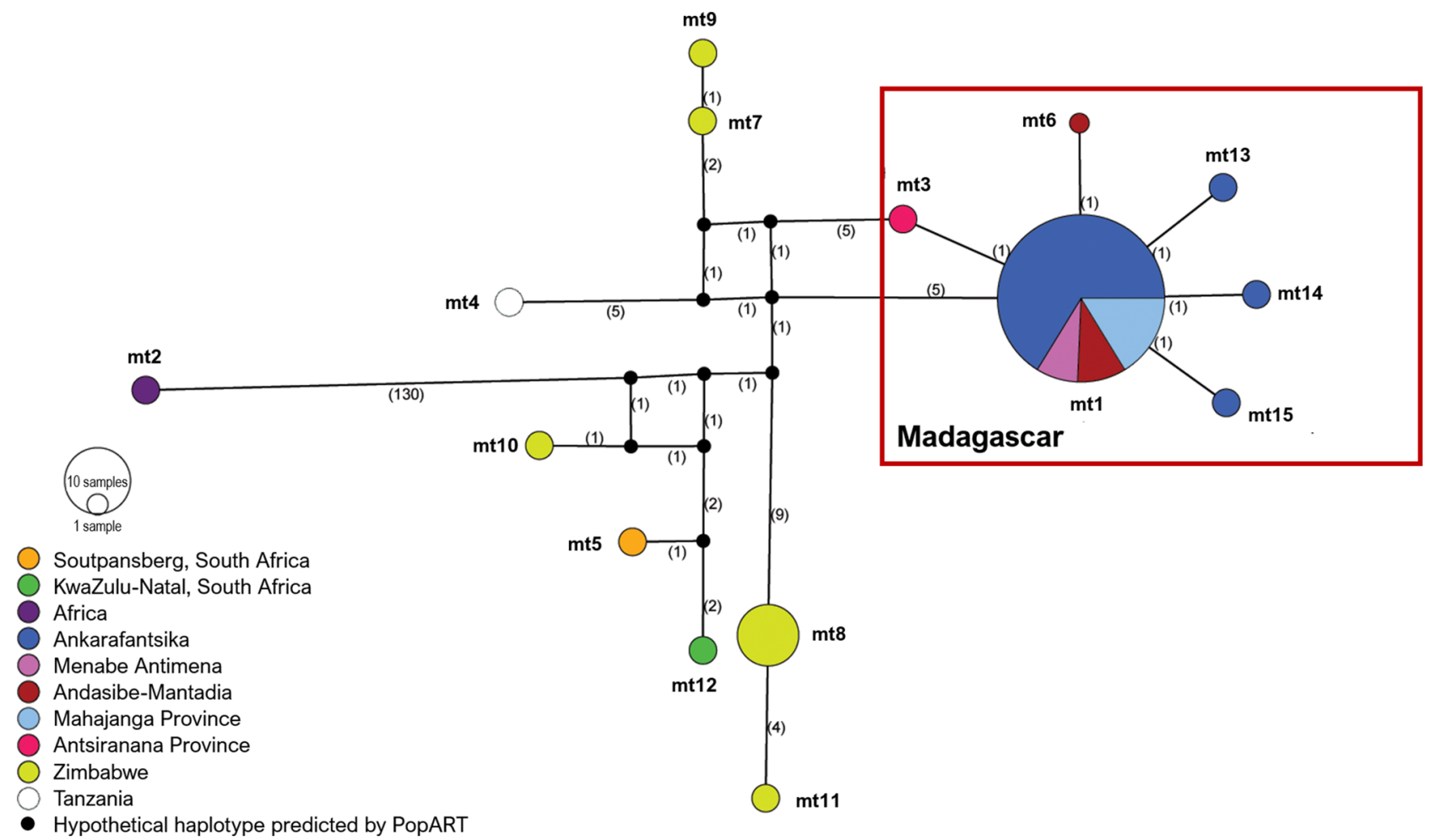

Figure 3. Median joining network of Malagasy bushpigs based on concatenated mtDNA (CR and $c y t b$ ). Coloured circles represent the haplotypes identified by DnaSP v $6^{65}$ with each colour represented by a location as indicated by the figure key, and the size of the circle is proportional to the frequency of each haplotype (with ' $m t^{\prime}$ ' as a prefix to indicate mitochondrial). Numbers in parentheses along the branches represents the mutational steps between each haplotype.

Haplotype structure of bushpigs from Madagascar. Haplotypes identified by DnaSP were assigned the prefixes ' $m t$ ' (concatenated mitochondrial DNA from Datasets 1a and 1b), 'CR' (control region), 'cytb' (cytochrome b), 'GPIP', and 'MC1R' followed by a designated number. MJN analysis of concatenated bushpig mtDNA sequences (Dataset $1 \mathrm{~b}$; Table 3) showed that the haplotypes of bushpigs from Madagascar clustered separately from mainland bushpigs (Figs. 3 and 4). A total of six closely related haplotypes were found from the concatenated data (Dataset 1b; Fig. 3); one haplotype ( $\mathrm{mtl}$ ) shared by Madagascar bushpigs from the Mahajanga Province in West-Northwest (Menabe Antimena, Ankarafantsika, and general Mahajanga Province), three unique haplotypes found in bushpigs from Ankarafantsika ( $\mathrm{mt13}, 14$, and 15), and one each from AndasibeMantadia (East Madagascar; mt6), and the Antsiranana Province (North Madagascar; mt3). Single-gene analysis of the CR and cytb (Supplementary Fig. S6 and Fig. S7) showed no shared haplotypes between bushpigs from Madagascar and mainland Africa. Both CR and cytb contributed the most to the genetic differentiation between these two groups (13 and 14 haplotypes, respectively) each with five haplotypes unique to Madagascar. In contrast, the nuclear GPIP and MC1R genes (Supplementary Fig. S8) were highly conserved between bushpigs showing respectively three (two found in Madagascar) and four haplotypes (three found in Madagascar), and provided the lowest resolution of bushpig relationships.

The above was supported by concatenated sequences in which both mtDNA genes were successfully sequenced (Dataset 1a; Table 3), showing that specimens from Madagascar clustered closely together and separately from mainland specimens (Supplementary Fig. S9). In this case, nine haplotypes were identified for bushpigs from Madagascar, and of these, four haplotypes here were classified as mt1 using Dataset 1b (Fig. 3). Two of these haplotypes were found only in the Ankarafantsika specimens and the general Mahajanga Province region. Based on MJN analysis which showed the close relatedness of specimens from across Madagascar (one mutational step between haplotypes), the occurrence of multiple bushpig introductions to the island is unlikely.

Regarding mainland bushpigs, based on Datasets $1 \mathrm{a}$ and $1 \mathrm{~b}$, five unique haplotypes $(\mathrm{mt} 7,8,9,10$, and 11) were identified in Zimbabwe bushpigs and were more distantly related to each other compared to bushpigs from Madagascar (higher number of substitutions; Fig. 3 and Supplementary Fig. S9). The Zimbabwe bushpgis were also genetically different from bushpigs sampled from the Soutpansberg (mt5), KwaZulu-Natal (mt12), and Tanzania (mt4). The Soutpansberg ( $\mathrm{mt} 5$ ) and KwaZulu-Natal (mt12) bushpigs were consistently grouped separately from other bushpigs from Madagascar in all other mtDNA analyses (Supplementary Fig. S6 and Fig. S7). These results suggest that bushpigs from the island are related to the specimens from the central region of southern Africa. However, the absence of genetic data from southern Tanzania and Mozambique also limits the resolution of the relatedness between bushpigs from other regions in mainland Africa and Madagascar. 


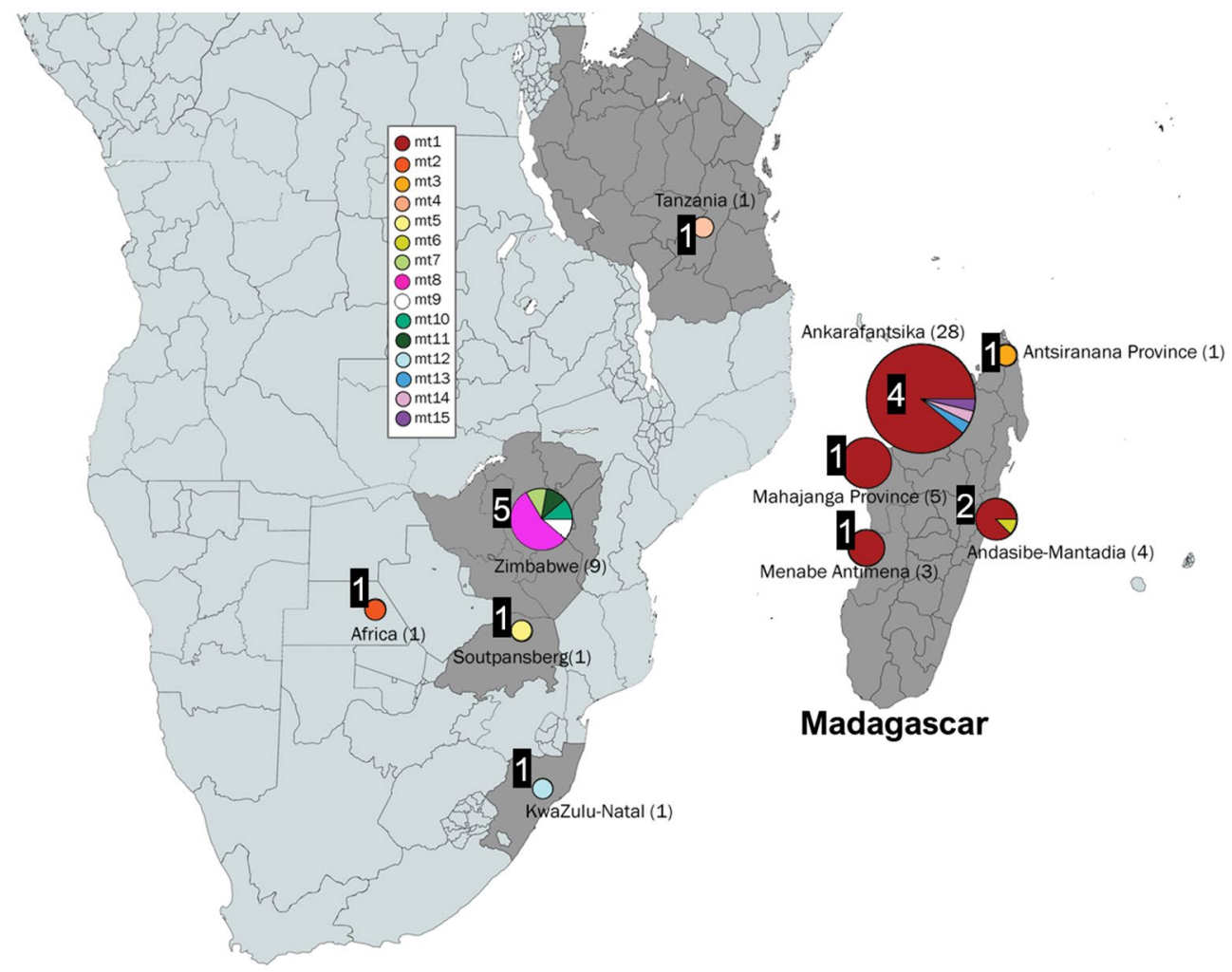

Figure 4. Malagasy bushpig mtDNA (CR and cytb) sequence by sampling location. Each colour indicates the different haplotypes (with ' $m$ t' as a prefix to indicate mitochondrial) with the number of individuals in each population shown in brackets. The number of different haplotypes within each location is highlighted by the black box adjacent to each circle. Figure includes an edited map generated by mapchart.net and haplotypes produced in PopART ${ }^{82}$ (https://popart.otago.ac.nz/index.shtml).

Overall, based on Dataset 1, the most frequent haplotype was $\mathrm{mt} 1$ found in $91.5 \%$ of bushpigs from Madagascar (Table 4). It was mostly found in specimens from "West" Madagascar (90.5\%), where mt13-15 were also found at low frequencies $(2.7-3.6 \%)$.

Haplotype structure and genetic diversity of three MHC loci. Median-Joining Network analysis found no specific relationship or clustering for $S L A-D Q B 1$ exon-2 sequences (Figs. 5 and 6). However, phylogenetic analysis suggests that certain haplotypes clustering together in the same clade may perform similar functions (as supertypes) due to shared antigen-binding sites. Most of these were shared within bushpigs (Fig. 7; groups 1,2, 3, and 4), while group 5 was shared between bushpigs and $P$. africanus, and group 6 was found in $B$. babyrussa only. Antigen-binding site Groups 2 and 5 were found in relatively low frequencies (average $3.4 \%$ and $2.3 \%$, respectively).

The highest genetic diversity (nucleotide; nt: 0.048; amino acid; AA: 0.117) was observed in the polymorphic $S L A-D Q B 1$ exon-2 region (Table 5) with 28 haplotypes-19 in bushpigs from Madagascar and 11 in mainland individuals (Supplementary Table S4). Only two haplotypes were shared between mainland and bushpigs from the island (DQB1-8 and DQB1-9). The most frequent of these was DQB1-8 (31.8\% of all bushpig specimens) which was found in specimens from Ankarafantsika (42.9\%), "East" Madagascar from Andasibe-Mantadia (25\%) and Soutpansberg on mainland Africa (Fig. 6; Supplementary Table S4). DQB1-4, -6, and -19 were also found in relatively high frequencies in Madagascar (11.4-20.5\%; Supplementary Table S4). The remaining 15 haplotypes were found in low frequencies (2.3-9.1\%), mostly from Ankarafantsika. The genetic diversity between Madagascar and mainland bushpigs was similar (nt: 0.043; amino acid; AA: 0.114 and mainland Africa nt: 0.046; AA: 0.098), although diversity appears lower when looking at specific sampling locations separately in Madagascar (Supplementary Table S4). Amongst the 28 haplotypes found in bushpigs, only one (DQB1-15; 6.8\%) was shared with another species (P. porcus). No existing sequence was found on the NBCI and IPD-MHC database (Supplementary Table S5).

Genetic distance analyses indicated that the haplotypes are also very distinct from those found on the mainland; genetic distance between Madagascar and mainland bushpig sequences ranged from 0.031 to 0.058 , while sequences from Madagascar (Ankarafantsika, Menabe Antimena, and Andasibe-Mantadia) had a genetic distance ranging from 0.026 to 0.035 (Supplementary Table S6).

In contrast to $S L A-D Q B 1$, the class II SLA-6 and class III BAG6 genes were more conserved with only two and four haplotypes found, respectively. For both genes, only one haplotype was found in Madagascar (SLA-6-1 


\begin{tabular}{|c|c|c|c|c|c|c|c|c|c|c|c|c|c|c|c|c|}
\hline \multirow{2}{*}{$\begin{array}{l}\text { Haplotype prefix } \\
\text { Location }\end{array}$} & \multirow[b]{2}{*}{$N$} & \multicolumn{15}{|l|}{ mt } \\
\hline & & 1 & 2 & 3 & 4 & 5 & 6 & 7 & 8 & 9 & 10 & 11 & 12 & 13 & 14 & 15 \\
\hline Madagascar & 42 & 88.1 & & 2.4 & & & 1.2 & & & & & & & 2.4 & 2.4 & 2.4 \\
\hline "West" Madagascar & 37 & 90.5 & & & & & & & & & & & & 2.7 & 2.7 & 2.7 \\
\hline Ankarafantsika & 28 & 87.5 & & & & & & & & & & & & 3.6 & 3.6 & 3.6 \\
\hline Menabe Antimena & 3 & 100 & & & & & & & & & & & & & & \\
\hline Mahajanga Province general & 6 & 100 & & & & & & & & & & & & & & \\
\hline $\begin{array}{l}\text { "East" Madagascar (Andasibe-Man- } \\
\text { tadia) }\end{array}$ & 4 & 87.5 & & & & & 12.5 & & & & & & & & & \\
\hline $\begin{array}{l}\text { "North" Madagascar (Antsiranana } \\
\text { Province) }\end{array}$ & 1 & & & 100 & & & & & & & & & & & & \\
\hline Mainland Africa & 13 & & 7.7 & & 7.7 & 7.7 & & 7.7 & 38.5 & 7.7 & 7.7 & 7.7 & 7.7 & & & \\
\hline Tanzania & 1 & & & & 100 & & & & & & & & & & & \\
\hline Zimbabwe & 9 & & & & & & & 11.1 & 55.6 & 11.1 & 11.1 & 11.1 & & & & \\
\hline KwaZulu-Natal, SA & 1 & & & & & & & & & & & & 100 & & & \\
\hline Soutpansberg, SA & 1 & & & & & 100 & & & & & & & & & & \\
\hline Africa & 1 & & 100 & & & & & & & & & & & & & \\
\hline Total (All bushpigs) & 54 & 68.5 & 1.9 & 1.9 & 1.9 & 1.9 & 0.9 & 1.9 & 9.3 & 1.9 & 1.9 & 1.9 & 1.9 & 1.9 & 1.9 & 1.9 \\
\hline
\end{tabular}

Table 4. Percentage of CR and cytb concatenated haplotypes found in bushpigs across Madagascar and mainland Africa. Percentages are based on the number of samples for each location. Haplotypes correspond to those labelled from Dataset la (Fig. 3).

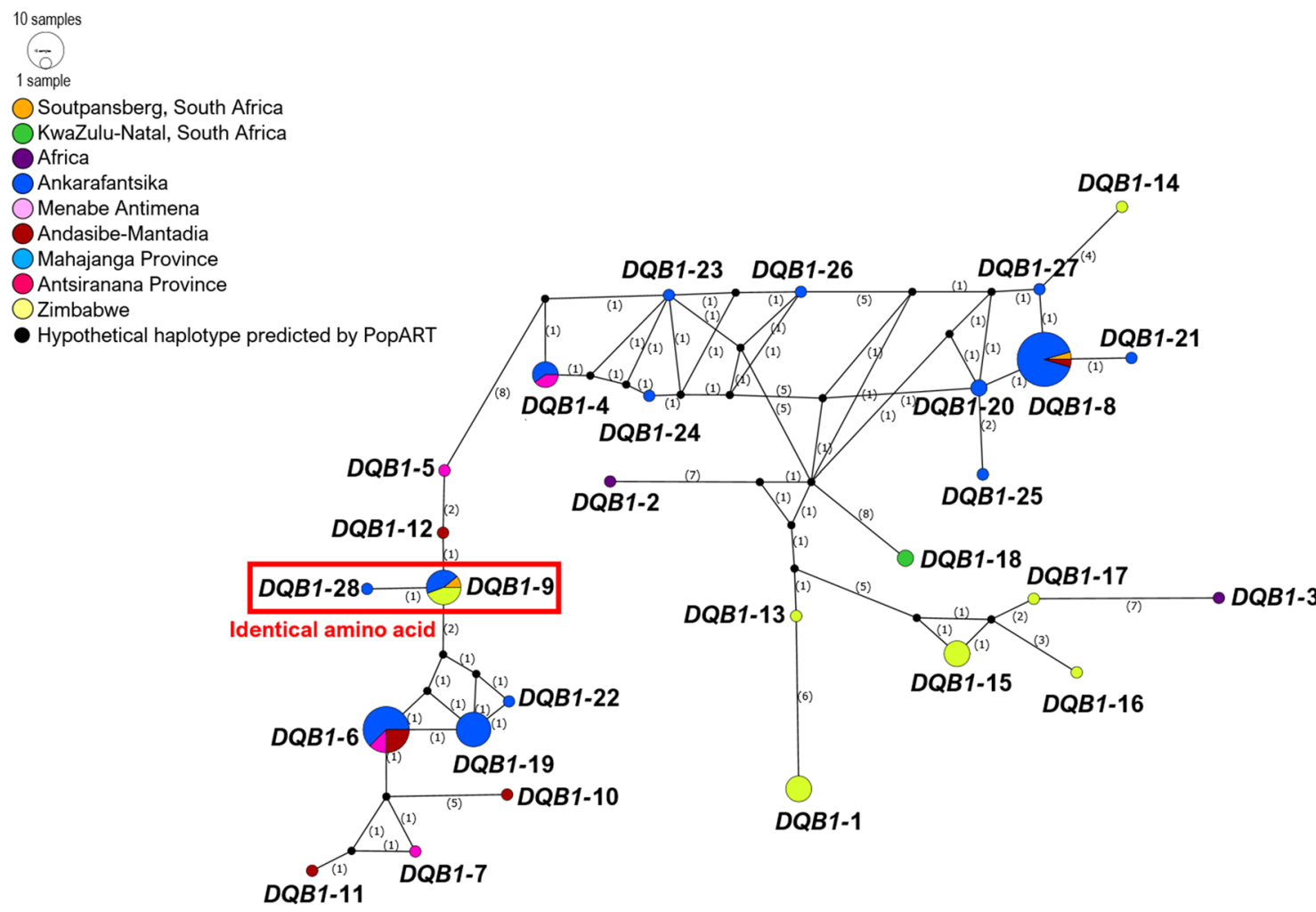

Figure 5. Median joining network of Malagasy bushpigs based on MHC loci SLA-DQB1 exon-2 sequence. Coloured circles represent the haplotypes identified by DnaSP v $6{ }^{65}$ with each colour represented by a location as indicated by the figure key, and the size of the circle is proportional to the frequency of each haplotype. Numbers in parentheses along the branches represents the mutational steps between each haplotype. Haplotypes with the same translated amino acid sequence are outlined.

and BAG6-1; Supplementary Fig. S10 and Fig. S11), which was similarly found in high frequencies on mainland Africa as well (91.7-100\% in SLA-6 and 83.3-92.3\% in BAG6; Supplementary Table S5 and Fig. S6). Interestingly, these were also found in other sub-Saharan African species (P. porcus, H. meinertzhageni, and P. africanus) and was shared with B. babyrussa through identical amino acid translation (SLA-6-7). Within BAG6 (Supplementary 


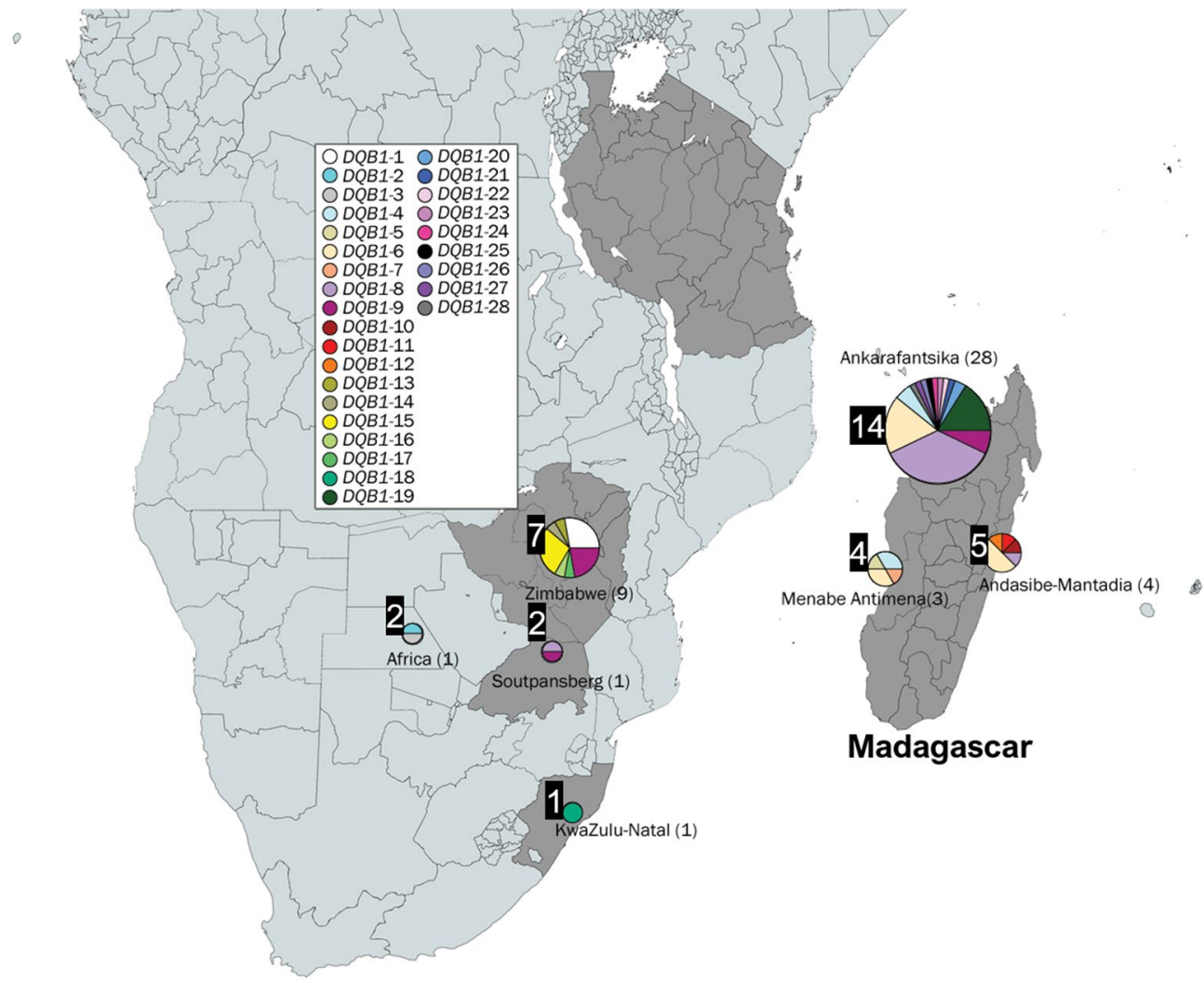

Figure 6. Malagasy bushpig MHC class II SLA-DQB1 sequences by sampling location. Each colour indicates the different haplotypes with the number of individuals in each population shown in brackets. The number of different haplotypes within each location is highlighted by the black box adjacent to each circle. Figure includes an edited map generated by mapchart.net and haplotypes produced in PopART ${ }^{82}$ (https://popart.otago.ac.nz/ index.shtml).

Table S7), BAG6-3 to 5 were found in lower frequencies but the aforementioned and BAG6-6 produced the same amino acid sequence as the most common haplotype (BAG6-1) and thus appears fairly conserved across mainland and Madagascar bushpigs and not found in other species. Based on amino acid translation, haplotypes BAG6-1 and BAG6-6 were found in other sub-Saharan African species and B. babyrousa, respectively. BAG6-7 and BAG6-8 were only found in P. tajacu. The overall genetic diversity of SLA-6 was lower (nt: 0.03; AA: 0.04; Table 6) than BAG6 (nt: 0.017; AA: 0.01; Table 6), although the diversity was lower in BAG6 when only considering bushpigs (nt: 0.004; AA: 0.004). However, the S.E. for both these genes was high, possibly due to the low number of haplotypes found. In addition, the number of variable sites was extremely low. BLAST searches also found three identical matches in public databases, with $S L A-6-2$ matching several $S L A-6$ haplogroups of $S$. scrofa, SLA-6-4 being identical to $S L A-6^{\star}$ 10:01 (Supplementary Table S9), and BAG6-2 being identical to an existing S. scrofa sequence (Supplementary Table S10). These sequences were also shared with other Sus species. The 86 SLA-DQB1, 74 SLA-6, and 65 BAG6 sequences were submitted under GenBank accession numbers: MT853335-MT853419, MT853262-MT853334, and MT853420-MT853483.

Selection analysis of MHC in bushpigs from Madagascar. Several SLA-DQB1 sites were found to be under (diversifying) selection when considering all haplotypes or subcategories (mainland Africa or Madagascar; Fig. 8). Two and one sites were detected under diversifying selection respectively in mainland bushpigs (8G: MEME $P$-value: 0.03, REL BF: 208.31; 21G: MEME $P$-value: 0.03, SLAC $P$-value: 0.13 , REL BF: $>50$ ), and bushpigs from Madagascar (52F: FEL $P$-value: 0.16, SLAC $P$-value: 0.16 ). Site 21 was the most diverse in mainland bushpigs, coding for up to four different residues, the same site only coding for one residue in bushpigs from Madagascar. In contrast, site 52 coded for up to five different residues in bushpigs from Madagascar, compared to only three in mainland bushpigs (Fig. 8). In addition, one site was significant for purifying selection in bushpigs from Madagascar (15G: FEL P-value: 0.06, SLAC P-value: 0.13, REL BF: $>50$ ), and was conserved across all haplotypes.

Results show that the SLA-6 exon-2 region was highly conserved (Supplementary Fig. S12), with two sites subjected to purifying selection in more than two methods (42 N: FEL $P$-value: 0.07, SLAC P-value: 0.25 ; and 65D: FEL $P$-value: 0.09, SLAC P-value: 0.25 ) and one significant for diversifying selection (57R: FEL $P$-value: 0.25, MEME: 0.23, REL Bayes factor: 346.4). Site 57 coded for two different residues (arginine or serine) but was conserved in bushpig haplotypes (Supplementary Fig. S12). BAG6 was similarly conserved (Supplementary Fig. S13); when all haplotypes were considered, we detected one site evolving under purifying selection (26I: FEL 


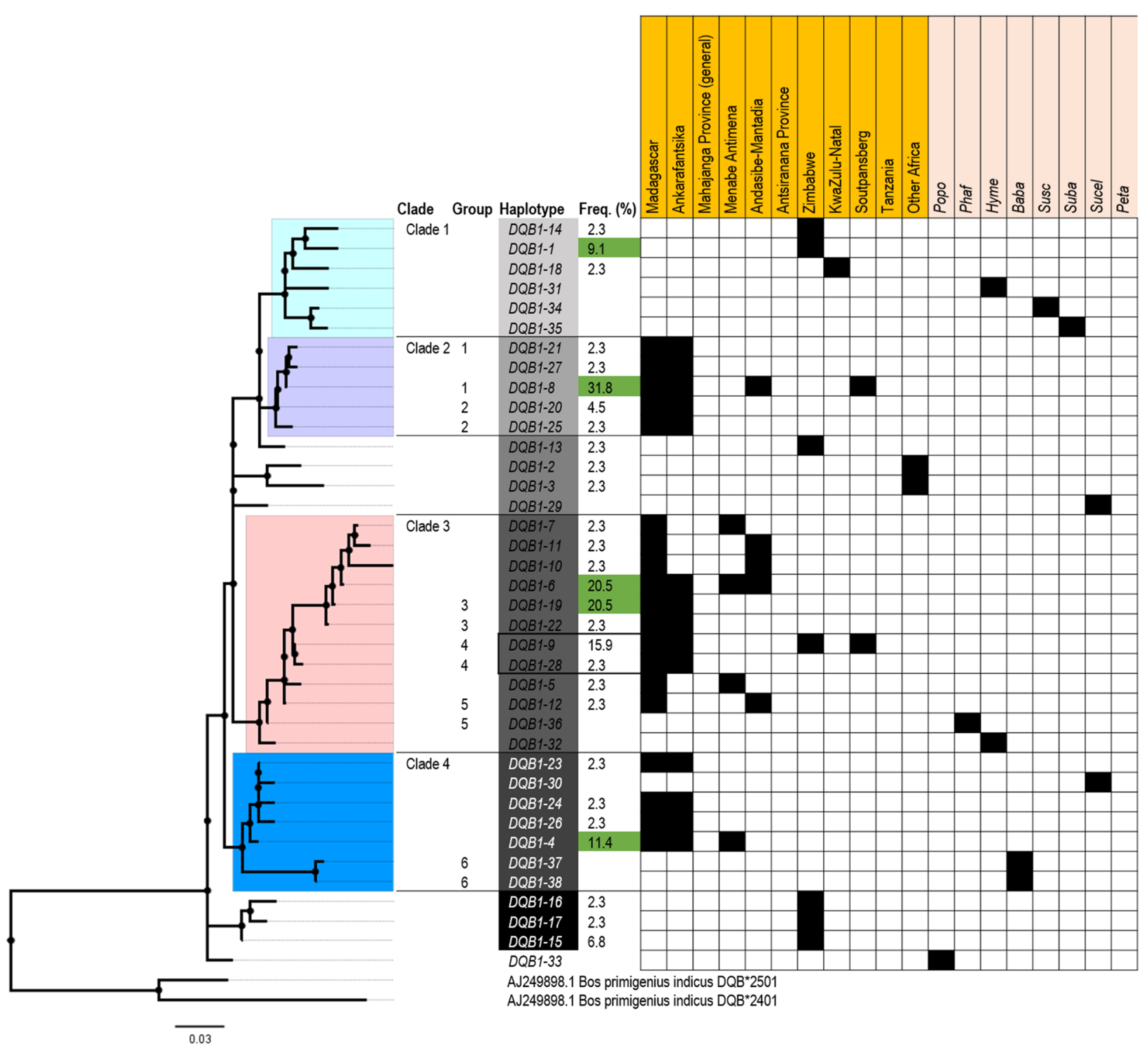

Figure 7. Phylogenetic analysis of the $S L A-D Q B 1$ haplotypes including all haplotypes (and samples). Haplotype numbers are aligned to their position on the maximum likelihood tree with their frequencies (\%). The presence of each haplotype in the specific localities is indicated by the shaded box. Group numbers indicate identical antigen-binding sites of the relevant haplotypes.

$P$-value: 0.04, SLAC $P$-value: 0.17$)$ and three diversifying selected sites (47P: FEL $P$-value: 0.20, REL BF: 98.71; 94P: FEL $P$-value: 0.07, MEME $P$-value: 0.04, REL BF: 9478.98; and 113A: FEL $P$-value: 0.24, REL BF: 90.14). Sites 47, 94 and 113 coded for two different residues each. No difference between mainland bushpigs and those from Madagascar were found for both SLA-6 and BAG6.

\section{Discussion}

Presence of bushpigs in Madagascar. The geographic origin of bushpigs, from the genus Potamochoerus, in Madagascar has been speculated for a considerable time-whether they were introduced and if so, from what area of Africa. Molecular evidence identified that bushpigs on the island are derived from the sub-Saharan Africa species, P. larvatus as a sister clade of $P$. porcus $^{67}$ and the Madagascar population originated from a lineage that is closest to the populations of the central region of southern Africa, perhaps related to the subspecies $P$. $l$. koiropotamus found predominantly in southern Africa ${ }^{15}$. The Mozambique Channel may have had formed a barrier to the direct passage of seafaring people from coastal Africa direct to Madagascar and this passage may have been more easily navigated via the Comoro Islands ${ }^{21}$; the later passage was an important trade route for sailing vessels for at least a portion of the Middle Age ${ }^{100}$.

As all Malagasy samples formed a well-supported monophyletic clade (Fig. 3 and Supplementary Fig. S9), our results do not support the idea that bushpigs in Madagascar originated from multiple African source populations. It remains possible, however, that additional haplotypes could have been identified with a greater geographical 


\begin{tabular}{|c|c|c|c|c|c|c|c|}
\hline & \multirow[b]{2}{*}{ nhap } & \multicolumn{3}{|l|}{ nt } & \multicolumn{3}{|l|}{ AA } \\
\hline & & $\mathbf{V}$ & mean & S.E & $\mathrm{V}$ & MEAN & S.E \\
\hline All & 38 & 43 & 0.048 & 0.008 & 28 & 0.117 & 0.023 \\
\hline Bushpigs & 28 & 31 & 0.046 & 0.008 & 21 & 0.115 & 0.025 \\
\hline Madagascar & 19 & 27 & 0.043 & 0.009 & 20 & 0.114 & 0.027 \\
\hline Ankarafantsika & 14 & 19 & 0.038 & 0.009 & 16 & 0.101 & 0.025 \\
\hline Mahajanga Province (general) & - & & & & & & \\
\hline Menabe Antimena & 4 & 14 & 0.031 & 0.008 & 13 & 0.09 & 0.025 \\
\hline "East" Madagascar (Andasibe-Mantadia) & 5 & 19 & 0.039 & 0.009 & 16 & 0.104 & 0.027 \\
\hline "North” Madagascar (Antsiranana Province) & - & & & & & & \\
\hline Mainland Africa & 11 & 28 & 0.046 & 0.009 & 18 & 0.098 & 0.024 \\
\hline Zimbabwe & 7 & 26 & 0.042 & 0.008 & 18 & 0.093 & 0.022 \\
\hline KwaZulu-Natal, SA & 1 & & & & & & \\
\hline Soutpansberg, SA & 2 & & & & & & \\
\hline Tanzania & - & 13 & 0.051 & 0.013 & 10 & 0.121 & 0.028 \\
\hline Africa & 2 & 9 & 0.035 & 0.012 & 7 & 0.083 & 0.032 \\
\hline
\end{tabular}

Table 5. Diversity analysis of bushpigs MHC class II SLA-DQB1 exon-2 sequence. Analysis was performed using the model T92 in MEGA $7^{89}$. The Poisson model was used for amino acid analysis. The number of haplotypes (nhap) for each category is shown, including mean diversity (and standard error; S.E) and variable sites (V) for nucleotide (nt) and amino acid (AA) sequences.

\begin{tabular}{|c|c|c|c|c|c|c|c|c|c|c|c|c|c|c|}
\hline & \multicolumn{7}{|l|}{ SLA6 } & \multicolumn{7}{|l|}{ BAG6 } \\
\hline & \multirow[b]{2}{*}{ nhap } & \multicolumn{3}{|l|}{ nt } & \multicolumn{3}{|c|}{ AA } & \multirow[b]{2}{*}{ nhap } & \multicolumn{3}{|l|}{ nt } & \multicolumn{3}{|c|}{ AA } \\
\hline & & $\mathbf{V}$ & Mean & S.E & $\mathbf{V}$ & Mean & S.E & & $\mathbf{V}$ & Mean & S.E & $\mathbf{V}$ & Mean & S.E \\
\hline All & 7 & 17 & 0.03 & 0.007 & 7 & 0.04 & 0.015 & 8 & 17 & 0.017 & 0.004 & 4 & 0.011 & 0.006 \\
\hline Bushpig & 2 & 2 & 0.007 & 0.005 & 1 & 0.011 & 0.011 & 4 & 3 & 0.004 & 0.002 & 1 & 0.004 & 0.004 \\
\hline Madagascar & 1 & & & & & & & 1 & & & & & & \\
\hline Ankarafantsika & 1 & & & & & & & 1 & & & & & & \\
\hline Mahajanga Province (general) & 1 & & & & & & & 1 & & & & & & \\
\hline Menabe Antimena & 1 & & & & & & & 1 & & & & & & \\
\hline $\begin{array}{l}\text { "East" Madagascar (Andasibe-Man- } \\
\text { tadia) }\end{array}$ & 1 & & & & & & & 1 & & & & & & \\
\hline $\begin{array}{l}\text { "North" Madagascar (Antsiranana } \\
\text { Province) }\end{array}$ & 1 & & & & & & & - & & & & & & \\
\hline Mainland Africa & 2 & 2 & 0.007 & 0.005 & 1 & 0.011 & 0.011 & 4 & 3 & 0.004 & 0.002 & 1 & 0.004 & 0.004 \\
\hline Zimbabwe & 1 & & & & & & & 3 & 2 & 0.004 & 0.002 & 1 & 0.005 & 0.005 \\
\hline KwaZulu-Natal, SA & 1 & & & & & & & 1 & & & & & & \\
\hline Soutpansberg, SA & 1 & & & & & & & 1 & & & & & & \\
\hline Tanzania & 1 & & & & & & & - & & & & & & \\
\hline Africa & 1 & & & & & & & 1 & & & & & & \\
\hline
\end{tabular}

Table 6. Diversity analysis of bushpigs MHC class I SLA-6 exon-2 and class III BAG6 loci. MEGA $7^{89}$ was used to perform genetic diversity analysis for SLA-6 and BAG6 based on the models K2 and JC, respectively. The Poisson model was used for amino acid analysis. The number of haplotypes (nhap) for each category is shown, including mean diversity (and standard error; S.E.) and variable sites (V) for nucleotide (nt) and amino acid (AA) sequences.

sampling, particularly in the far north (Antsiranana Province) and also the Comoro Islands (i.e., Grande Comore and Mayotte ${ }^{9,101}$ - - but evidence of bushpigs on this island are unverified reports and may have been mistaken for feral pigs ${ }^{101}$. BEAST analysis suggests that Malagasy bushpigs diverged from an African source population, that was closest to bushpigs from Zimbabwe, approximately 480,000 years ago. These populations are distinct from those other Zimbabwe specimens and those in KwaZulu-Natal, suggesting the existence of separate phylogeographic groups before their translocation into Madagascar. The estimates does not exceed the time to most recent common ancestor of Potamochoerus (approximately $2.71 \mathrm{Ma}{ }^{67}$. The time of divergence between Malagasy and Zimbabwe bushpigs dramatically precedes that of any conclusive evidence of human occupation on Madagascar. Given that there is no evidence of bushpigs in Madagascar during the Holocene palaeontological or in pre-tenth-century archaeological records, the presence of bushpigs in Madagascar would have likely involved human intervention unless future fossil discoveries suggest otherwise. This early divergence indicates 

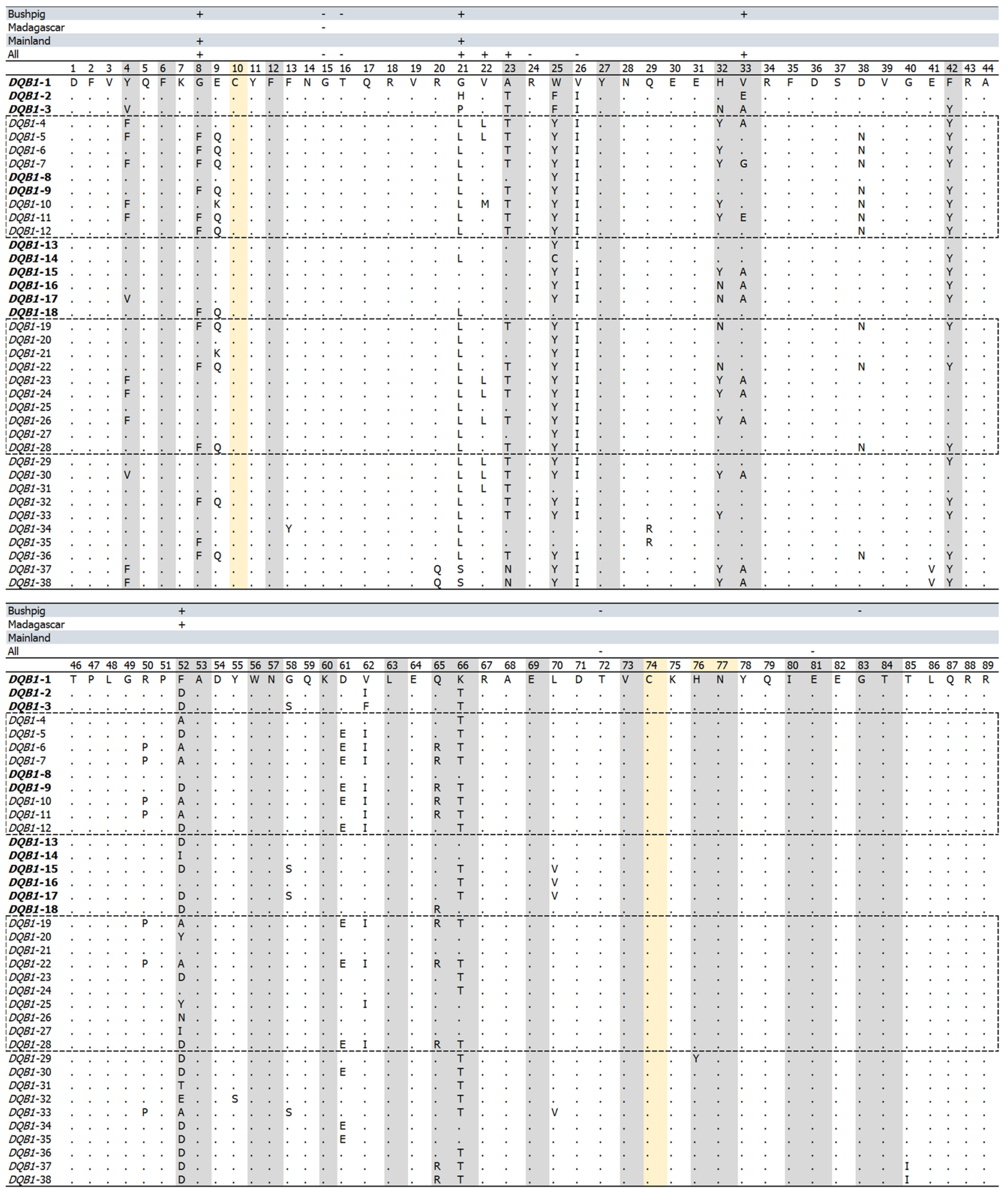

Figure 8. Amino-acid sequence and selection of $S L A-D Q B 1$ exon-2 haplotypes. Analysis was completed using DataMonkey HyPhy server ${ }^{83}$. Dots represent identical residues to DQB1-1 at the positions shown. Grey shaded sites indicate the antigen-binding sites and yellow indicate the conserved cysteines. Positions significant for positive $(+)$ or negative $(-)$ selection for at least two methods (MEME/FEL/SLAC/REL) are indicated for each population/location category. Dotted lines indicate haplotypes found in bushpigs and haplotypes in bold font are found in mainland bushpigs. 
that the Zimbabwe population does not represent the source population of Malagasy per-se. Altogether, our results indicate that to identify the source population of Malagasy bushpigs, future studies should collect additional samples from locations such as Mozambique, southern Tanzania, and offshore islands-specifically the Comoros, Mafia, and Zanzibar.

The study showed that mitochondrial DNA was useful in inferring the relationships of Malagasy bushpigs but this was not the case for the nuclear DNA GPIP and MC1R. Both the phylogenetic topologies produced for GPIP and $M C 1 R$ were less resolved. The $M C 1 R$ gene was useful in discerning coat colour for breeds of domestic pigs but not in bushpigs, however further studies identifying other melanin producing genes may be suitable for similar studies $^{50,59,102,103}$. The usage of GPIP was also not informative for distinguishing between bushpig populations as for domestic pig breeds which was valuable in supporting information about domestication ${ }^{48,49}$. Sequencing of additional mitochondrial genes could also provide a more comprehensive insight into the divergence of bushpigs from Madagascar and the mainland.

Immunogenetic diversity of bushpigs from Madagascar. Our results show that Malagasy bushpigs have maintained similar levels of and unique genetic diversity within the important MHC class II SLA-DQB1 ABS through diversifying selection when compared to mainland animals (Fig. 8). This suggests that founder effects, such as genetic drift and founder population size ${ }^{12,28,104}$, had minimal effect on the SLA-DQB1 ABS and the adaptation to environmental challenges after the introduction to Madagascar may have driven the rise of new alleles and maintenance of genetic diversity. Most samples here are also from the tropical zones of Madagascar in contrast to the arid and temperate zones of Zimbabwe and southern Africa ${ }^{105}$. It is possible that the prevalence, abundance, and infection of novel parasites, driven by specific precipitation and temperature in Madagascar influenced MHC allele frequencies as has been suggested for other species ${ }^{87,106,107}$. In comparison, the retention of ancestral SLA-DQB1 ABS amongst Malagasy and mainland bushpigs may indicate the necessity to combat common pathogens such as as Taenia solium ${ }^{108,109}$, Trichinella ${ }^{110}$, and Burkloderia ${ }^{111}$. However, detailed studies of bushpigs are still limited, particularly due to their elusive behaviour. Investigations into parasitic infections in both the mainland and Madagascar, along multiple habitat ranges, and pathogen-associated studies could provide in-depth insights into the roles of specific haplotypes of MHC genes ${ }^{106,112,113}$.

In contrast to the above, the conserved SLA-6 haplotypes found in some of these species when observing amino acid translations (SLA-6-1, -4, and -7 were found in five genera: P. larvatus, P. africanus, H. meinertzahgeni, S. scrofa [wild boar], and B. babyrussa; and the bushpig specimen from Duisburg Zoo was identical to $S$. celebensis) are expected as this gene is often described as monomorphic ${ }^{114}$. SLA-6 has a wide tissue-expression but is the least overall transcribed non-classical genes ${ }^{114}$ with potential roles as a membrane-anchored glycoprotein and may have roles specific to each species ${ }^{115}$. The lack of genetic diversity of the SLA-6 exon-2 region, coding for the alpha-1 domain, provides little support for species-specific functions and additional sequencing of the alpha-2 domain may provide more information. There is also potential for the SLA non-classical genes to have similar functions to those described in humans (HLA-E, HLA-F, and HLA-G) such as cell population regulation (e.g. impair T cell proliferation and cytotoxicity ${ }^{116}$, apoptosis induction ${ }^{117}$ ), and possibly immunomodulation during pregnancy ${ }^{118}$.

The class III BAG6 gene was highly conserved and indicates a retention of these haplotypes across Suidae species due to similar functions, and the low diversity found should not be due to founder effects. The Class III $B A G 6$ gene has been shown to play a role in the presentation of MHC class I on the cell surface and protects against cell death by metabolising defective ribosomal products ${ }^{119}$. The importance of this gene in African swine fever infection has been implicated in the ability of viral genes to exploit host genes to evade host immunity ${ }^{60}$. African swine fever is known to asymptomatically infect bushpigs but can cause high mortality rates in species of the genus Sus ${ }^{120}$. Due to the high conservation between the sequences, it is highly likely that the role of BAG6 in ASFV resistant is small. Identical amino acid sequences in some haplotypes (BAG6-1, -3, -5, -6) only present in sub-Saharan African species, are distinct from those found in Sus. This may suggest functions that are different between genera. African swine fever infection in other species such as B. babyrussa and peccaries have been poorly studied and are suggested to not be affected by ASFV ${ }^{121,122}$. It is possible that mutations in genes can reduce activity or interfere with ASFV production ${ }^{60}$ and the role of BAG6 in ASFV resistance should be studied in the context of other Suidae and Tayassuidae species as well.

\section{Conclusion}

The current study provided genetic evidence that the bushpigs samples obtained in Madagascar are Potamochoerus larvatus which originated from mainland Africa and there was no genetic differentiation between eastern and western Malagasy bushpigs as suggested by previous morphological work. The introduction of bushpigs in Madagascar was associated with few maternal lineages and based on the current sampling seem closest to the sampled natural populations of Zimbabwe, but this conclusion is preliminary until more detailed phylogeographic data is available from other areas of eastern and south-eastern Africa, including southern Tanzania and Mozambique. The MHC sequences examined also showed differences between bushpigs from mainland Africa and Madagascar, with few haplotypes of the polymorphic SLA-DQB1 shared between the two groups, suggesting they are undergoing diversification from their mainland ancestors. This also indicates that the introduction and isolation of bushpigs in Madagascar did not severely reduce their immunogenetic repertoire and appear to facilitate adaptation to new environments. Additional sequencing of specimens from other locations around Madagascar, as well as eastern Africa, is needed to provide a more in-depth indication into the source population of bushpigs introduced to Madagascar. 


\section{Data availability}

The CR, cytb, GPIP, MC1R, SLA-DQB1, SLA-6, and BAG6 sequences generated during the current study are available in the GenBank repository under the GenBank accession numbers: MT853484-MT853538, MT864081MT864142, MT864030-MT864080, MT864143-MT86419, MT853335-MT853419, MT853262-MT853334, and MT853420-MT853483, respectively.

Received: 12 August 2020; Accepted: 9 November 2020

Published online: 26 November 2020

\section{References}

1. Hansford, J. et al. Early holocene human presence in Madagascar evidenced by exploitation of avian megafauna. Sci. Adv. 4, 1-7 (2018).

2. Douglass, K. et al. A critical review of radiocarbon dates clarifies the human settlement of Madagascar. Quat. Sci. Rev. 221, 105878 (2019).

3. Pierron, D. et al. Genomic landscape of human diversity across Madagascar. Proc. Natl. Acad. Sci. USA 114, E6498-E6506 (2017).

4. Anderson, A. et al. New evidence of megafaunal bone damage indicates late colonization of Madagascar. PLoS ONE 13, 1-14 (2018).

5. Blench, R. New palaeozoogeographical evidence for the settlement of Madagascar. Azania Archaeol. Res. Afr. 42, 69-82 (2007).

6. Beaujard, P. The first migrants to Madagascar and their introduction of plants: Linguistic and ethnological evidence. Azania 46, 169-189 (2011).

7. Rakotozafy, L. M. A. \& Goodman, S. M. Contribution à l'étude zooarchéologique de la région du Sud-ouest et extrême Sud de Madagascar sur la base des collections de l'ICMAA de l'Université d'Antananarivo. Taloha 14-15 (2005).

8. Boivin, N., Crowther, A., Helm, R. \& Fuller, D. Q. East Africa and Madagascar in the Indian Ocean world. J. World Prehistory 26, 213-281 (2013).

9. Wright, H. T. et al. Early Seafarers of the Comoro Islands: The Dembeni Phase of the IXth-Xth Centuries AD. Azania Archaeol. Res. Africa 19, 13-59 (1984).

10. Krause, D. W. et al. Late cretaceous terrestrial vertebrates from Madagascar: Implications for Latin American biogeography 1. Ann. Missouri Bot. Gard. 93, 178-208 (2006).

11. Roger, F., Ratovonjato, J., Vola, P. \& Uilenberg, G. Ornithodoros porcinus ticks, bushpigs, and African swine fever in Madagascar. Exp. Appl. Acarol. 25, 263-269 (2001).

12. Sommer, S. The importance of immune gene variability (MHC) in evolutionary ecology and conservation. Front. Zool. 2, 16 (2005).

13. Venter, J., Ehlers-Smith, Y. \& Seydack, A. Potamochoerus larvatus-Bushpig. 1-5 (The Red List of Mammals of South Africa, Swaziland and Lesotho, 2016).

14. Andrianjakarivelo, V. Artiodactyla: Potamochoerus larvatus, Bush Pig. In The Natural History of Madagascar (eds Goodman, S. M. \& Benstead, J. B.) 1365-1367 (The University of Chicago Press, Chicago, 2003).

15. Grubb, P. The Afrotropical Suids (Phacochoerus, Hylochoerus, and Potamochoerus). In Pigs, Peccaries, and Hippos: Status Survey and Conservation Action Plan (ed. William, L. R. O.) 66-101 (International Union for the Conservation of Nature, Gland, 1993).

16. Forsyth, C. I. 5. On the Species of Potamocherus, the Bush-Pigs of the Ethiopian Region. Proc. Zool. Soc. London 65, 359-370 (2009).

17. Vercammen, P., Seydack, A. \& Oliver, W. The Bush Pigs (Potamochoerus larvatus and P. porcus). In Pigs, Peccaries, and Hippos: Status Survey and Conservation Action Plan (ed. William, L. R. O.) 93-101 (IUCN SSC Pigs and Peccaries Specialist Group and IUCN SSC Hippo Specialist Group, Gland, 1993).

18. Funaioli, U. \& Simonetta, A. M. The mammalian fauna of the somali republic: Status and conservation problems. Monit. Zool. Ital. Suppl. 1, 285-347 (1966).

19. Stuart, C. \& Stuart, T. Chris and Tilde Stuart's field guide to the mammals of southern Africa (R. Curtis Books Pub., Sanibel Island, 1988).

20. Blench, R. M. Archaeology, Language, and the African Past (Altamira Press, Lanham, 2006).

21. Alpers, E. A. Littoral society in Mozambique. In Cross Currents and Community Networks: The History of the Indian Ocean World (eds Ray, H. P. \& Alpers, E. A.) 123-141 (Oxford University Press, Oxford, 2007).

22. Oura, C. A. L., Powell, P. P. \& Parkhouse, R. M. E. African swine fever: A disease characterized by apoptosis. J. Gen. Virol. 79, 1427-1438 (1998)

23. Ravaomanana, J. et al. Assessment of interactions between African swine fever virus, bushpigs (Potamochoerus larvatus), Ornithodoros ticks and domestic pigs in north-western Madagascar. Transbound. Emerg. Dis. 58, 247-254 (2011).

24. Cecchi, G. \& Mattioli, R. C. Global geospatial datasets for African trypanosomiasis management: a review. Progr. Afr. Trypanos. Tech. Sci. Ser. 9, 1-39 (2009).

25. Munangandu, H. M., Siamudaala, V., Munyeme, M. \& Nalubamba, K. S. A review of ecological factors associated with the epidemiology of wildlife Trypanosomiasis in the Luangwa and Zambezi Valley Ecosystems of Zambia. Interdiscip. Perspect. Infect. Dis. 2012, 1-13 (2012)

26. Gibbs, E. P. The public health risks associated with wild and feral swine. Rev. Sci. Tech. 16, 594-598 (1997)

27. Patton, D. \& Gu, H. China has culled more than 900,000 pigs due to African swine fever. Reuters (2018).

28. Ploshnitsa, A. I., Goltsman, M. E., Macdonald, D. W., Kennedy, L. J. \& Sommer, S. Impact of historical founder effects and a recent bottleneck on MHC variability in Commander Arctic foxes (Vulpes lagopus). Ecol. Evol. 2, 165-180 (2012).

29. Klein, J. Origin of major histocompatibility complex polymorphism: The trans-species hypothesis. Hum. Immunol. 19, 155-162 (1987).

30. Ho, C. S. et al. Nomenclature for factors of the SLA system, update 2008. Tissue Antigens 73, 307-315 (2009).

31. Renard, C. et al. The genomic sequence and analysis of the swine major histocompatibility complex. Genomics $\mathbf{8 8}$, 96-110 (2006).

32. Ka, S. et al. HLAscan: Genotyping of the HLA region using next-generation sequencing data. BMC Bioinform. 18, 1-11 (2017).

33. Fan, W. et al. Shared class II MHC polymorphisms between humans and chimpanzees. Hum. Immunol. 26, 107-121 (1989).

34. Piertney, S. B. \& Oliver, M. K. The evolutionary ecology of the major histocompatibility complex. Heredity (Edinb). 96, 7-21 (2006).

35. Flajnik, M. F., Canel, C., Kramer, J. \& Kasahara, M. Which came first, MHC class I or class II?. Immunogenetics 33, 295-300 (1991).

36. Borghans, J. A. M., Beltman, J. B. \& De Boer, R. J. MHC polymorphism under host-pathogen coevolution. Immunogenetics 55, $732-739$ (2004)

37. Spurgin, L. G. \& Richardson, D. S. How pathogens drive genetic diversity: MHC, mechanisms and misunderstandings. Proc. Biol. Sci. 277, 979-988 (2010). 
38. Hughes, A. L. \& Nei, M. Nucleotide substitution at major histocompatibility complex class II loci: Evidence for overdominant selection. Proc. Natl. Acad. Sci. 86, 958-962 (1989).

39. Hughes, A. L. \& Nei, M. Evolution of the major histocompatibility complex: Independent origin of nonclassical class I genes in different groups of mammals. Mol. Biol. Evol. 6, 559-579 (1989).

40. Penn, D. J. \& Ilmonen, P. Major histocompatibility complex (MHC). in Encyclopedia of Life Sciences 1-7 (John Wiley \& Sons, Ltd, 2001). https://doi.org/10.1038/npg.els.0000919.

41. Bonneaud, C., Pérez-Tris, J., Federici, P., Chastel, O. \& Sorci, G. Major histocompatibility alleles associated with local resistance to malaria in a passerine. Evolution (N. Y.). 60, 383 (2006).

42. Schatz, G. E. Endemism in the Malagasy flora. In Diversity and Endemism in Madagascar (eds Lourenço, W. R. \& Goodman, S. M.) $1-10(2000)$.

43. Lowden, S. et al. Application of Sus scrofa microsatellite markers to wild suiformes. Conserv. Genet. 3, 347-350 (2002).

44. Gongora, J., Morales, S., Bernal, J. E. \& Moran, C. Phylogenetic divisions among Collared peccaries (Pecari tajacu) detected using mitochondrial and nuclear sequences. Mol. Phylogenet. Evol. 41, 1-11 (2006).

45. Lee, C. et al. Inferring the evolution of the major histocompatibility complex of wild pigs and peccaries using hybridisation DNA capture-based sequencing. Immunogenetics 70, 401-417 (2018).

46. Kim, K. I. et al. Phylogenetic relationships of Asian and European pig breeds determined by mitochondrial DNA D-loop sequence polymorphism. Anim. Genet. 33, 19-25 (2002).

47. Irwin, D. M., Kocher, T. D. \& Wilson, A. C. Evolution of the Cytochrome b gene of mammals. J. Mol. Evol. 32, 128-144 (1991).

48. Giuffra, E. et al. The origin of the domestic pig: independent domestication and subsequent introgression. Genetics 154, 1785$1791(2000)$.

49. Ishiguro, N., Naya, Y., Horiuchi, M. \& Shinagawa, M. A Genetic method to distinguish crossbred inobuta from Japanese Wild Boars. Zool. Sci. 19, 1313-1319 (2002).

50. Fajardo, V. et al. Differentiation of European wild boar (Sus scrofa scrofa) and domestic swine (Sus scrofa domestica) meats by PCR analysis targeting the mitochondrial D-loop and the nuclear melanocortin receptor 1 (MC1R) genes. Meat Sci. 78, 314-322 (2008).

51. Firestone, K. B. Phylogenetic relationships among quolls revisited: The mtDNA control region as a useful tool. J. Mamm. Evol. 7, 1-22 (2000).

52. Randi, E. et al. Evolution of the mitochondrial DNA control region and cytochrome b genes and the inference of phylogenetic relationships in the avian genus Lophura (Galliformes). Mol. Phylogenet. Evol. 19, 187-201 (2001).

53. Jiang, J. et al. Mitochondrial genome and nuclear markers provide new insight into the evolutionary history of macaques. PLoS ONE 11, 1-19 (2016).

54. Chen, L. et al. Intraspecific mitochondrial genome comparison identified CYTB as a high-resolution population marker in a new pest Athetis lepigone. Genomics 111, 744-752 (2019).

55. Gongora, J. et al. Phylogenetic relationships of Australian and New Zealand feral pigs assessed by mitochondrial control region sequence and nuclear GPIP genotype. Mol. Phylogenet. Evol. 33, 339-348 (2004).

56. Wang, J. et al. Phylogenetic relationships of pig breeds from Shandong province of China and their influence by modern commercial breeds by analysis of mitochondrial DNA sequences. Ital. J. Anim. Sci. 9, 248-254 (2010).

57. García, G., Vergara, J. \& Lombardi, R. Genetic characterization and phylogeography of the wild boar Sus scrofa introduced into Uruguay. Genet. Mol. Biol. 34, 329-337 (2011).

58. Lopez, J., Hurwood, D., Dryden, B. \& Fuller, S. Feral pig populations are structured at fine spatial scales in tropical Queensland, Australia. PLoS One 9, e91657 (2014).

59. Dun, G., Li, X., Cao, H., Zhou, R. \& Li, L. Variations of melanocortin receptor 1 (MC1R) gene in three pig breeds. J. Genet. Genomics 34, 777-782 (2007).

60. Chang, A. C. Y. et al. Phenotype-based identification of host genes required for replication of African swine fever virus. J. Virol. 80, 8705-8717 (2006).

61. Bitzer, A., Basler, M. \& Groettrup, M. Chaperone BAG6 is dispensable for MHC class I antigen processing and presentation. Mol. Immunol. 69, 99-105 (2016).

62. Stam, M. et al. Centromeric/pericentromeric junction within the MHC locus on chromosome 7 in pig. In XXXI Conference of the International Society for Animal Genetics, Amsterdam, Netherlands (2008).

63. Groenen, M. A. M. et al. Analyses of pig genomes provide insight into porcine demography and evolution. Nature 491, 393-398 (2012).

64. Stucky, B. J. SeqTrace: A graphical tool for rapidly processing DNA sequencing chromatograms. J. Biomol. Tech. 23, 90-93 (2012).

65. Rozas, J. et al. DnaSP 6: DNA sequence polymorphism analysis of large data sets. Mol. Biol. Evol. 34, 3299-3302 (2017).

66. Watanobe, T. et al. Genetic relationship and distribution of the Japanese wild boar (Sus scrofa leucomystax) and Ryukyu wild boar (Sus scrofa riukiuanus) analysed by mitochondrial DNA. Mol. Ecol. 8, 1509-1512 (1999).

67. Gongora, J. et al. Rethinking the evolution of extant sub-Saharan African suids (Suidae, Artiodactyla). Zool. Scr. 40, 327-335 (2011).

68. Larson, G. et al. Phylogeny and ancient DNA of Sus provides insights into neolithic expansion in Island Southeast Asia and Oceania. Proc. Natl. Acad. Sci. 104, 4834-4839 (2007).

69. Mona, S., Randi, E. \& Tommaseo-Ponzetta, M. Evolutionary history of the genus Sus inferred from Cytochrome $b$ sequences. Mol. Phylogenet. Evol. 45, 757-762 (2007).

70. Niebert, M. \& Tönjes, R. R. Evolutionary spread and recombination of porcine endogenous retroviruses in the suiformes. J. Virol. 79, 649-654 (2005).

71. Gongora, J. \& Moran, C. Nuclear and mitochondrial evolutionary analyses of Collared, White-lipped, and Chacoan peccaries (Tayassuidae). Mol. Phylogenet. Evol. 34, 181-189 (2005).

72. Hassanin, A. et al. Pattern and timing of diversification of Cetartiodactyla (Mammalia, Laurasiatheria), as revealed by a comprehensive analysis of mitochondrial genomes. C. R. Biol. 335, 32-50 (2012).

73. Wu, G. S. et al. Population phylogenomic analysis of mitochondrial DNA in wild boars and domestic pigs revealed multiple domestication events in East Asia. Genome Biol. 8, R245 (2007).

74. Thompson, J. D., Higgins, D. G. \& Gibson, T. J. CLUSTAL W: Improving the sensitivity of progressive multiple sequence alignment through sequence weighting, position-specific gap penalties and weight matrix choice. Nucleic Acids Res. 22, 4673-4680 (1994).

75. Vaidya, G., Lohman, D. J. \& Meier, R. SequenceMatrix: Concatenation software for the fast assembly of multi-gene datasets with character set and codon information. Cladistics 27, 171-180 (2011).

76. Gadagkar, S. R., Rosenberg, M. S. \& Kumar, S. Inferring species phylogenies from multiple genes: Concatenated sequence tree versus consensus gene tree. J. Exp. Zool. B. Mol. Dev. Evol. 304, 64-74 (2005).

77. Tonini, J., Moore, A., Stern, D., Shcheglovitova, M. \& Ortí, G. Concatenation and species tree methods exhibit Statistically indistinguishable accuracy under a range of simulated conditions. PLoS Curr. 7, 1-15 (2015).

78. Arcila, D., Petry, P. \& Ortí, G. Phylogenetic relationships of the family Tarumaniidae (Characiformes) based on nuclear and mitochondrial data. Neotrop. Ichthyol. 16, 16-19 (2018). 
79. Kozlov, A. M., Darriba, D., Flouri, T., Morel, B. \& Stamatakis, A. RAxML-NG: A fast, scalable and user-friendly tool for maximum likelihood phylogenetic inference. Bioinformatics 35, 4453-4455 (2019).

80. Schwarz, G. Estimating the dimension of a model. Ann. Stat. 6, 461-464 (1978).

81. Keane, T. M., Creevey, C. J., Pentony, M. M., Naughton, T. J. \& Mclnerney, J. O. Assessment of methods for amino acid matrix selection and their use on empirical data shows that ad hoc assumptions for choice of matrix are not justified. BMC Evol. Biol. 6, 29 (2006).

82. Leigh, J. W. \& Bryant, D. POPART: Full-feature software for haplotype network construction. Methods Ecol. Evol. 6, 1110-1116 (2015).

83. Weaver, S. et al. Datamonkey 2.0: A modern web application for characterizing selective and other evolutionary processes. Mol. Biol. Evol. 35, 773-777 (2018).

84. Nei, M. \& Gojobori, T. Simple methods for estimating the numbers of synonymous and nonsynonymous nucleotide substitutions. Mol. Biol. Evol. 3, 418-426 (1986).

85. Murrell, B. et al. Detecting individual sites subject to episodic diversifying selection. PLoS Genet. 8, e1002764 (2012).

86. Pond, S. L. K. \& Frost, S. D. W. Not so different after all: A comparison of methods for detecting amino acid sites under selection. Mol. Biol. Evol. 22, 1208-1222 (2005).

87. Awadi, A. et al. Positive selection and climatic effects on MHC class II gene diversity in hares (Lepus capensis) from a steep ecological gradient. Sci. Rep. 8, 11514 (2018).

88. Garrigan, D. \& Hedrick, P. W. Perspective: Detecting adaptive molecular polymorphism: Lessons from the MHC. Evolution 57, $1707-1722(2003)$

89. Kumar, S., Stecher, G. \& Tamura, K. MEGA7: Molecular evolutionary genetics analysis version 7.0 for bigger datasets. Mol. Biol. Evol. 33, 1870-1874 (2016).

90. Tamura, K. Estimation of the number of nucleotide substitutions when there are strong transition-transversion and G+C-content biases. Mol. Biol. Evol. 9, 678-687 (1992).

91. Kimura, M. A simple method for estimating evolutionary rates of base substitutions through comparative studies of nucleotide sequences. J. Mol. Evol. 16, 111-120 (1980).

92. Jukes, T. H. \& Cantor, C. R. Evolution of protein molecules. In Mammalian Protein Metabolism, 21-132 (Elsevier, 1969). https ://doi.org/10.1016/B978-1-4832-3211-9.50009-7.

93. Bouckaert, R. et al. BEAST 2: A software platform for bayesian evolutionary analysis. PLoS Comput. Biol. 10, e1003537 (2014).

94. Kearse, M. et al. Geneious Basic: An integrated and extendable desktop software platform for the organization and analysis of sequence data. Bioinformatics 28, 1647-1649 (2012).

95. Lanfear, R., Frandsen, P. B., Wright, A. M., Senfeld, T. \& Calcott, B. PartitionFinder 2: New methods for selecting partitioned models of evolution for molecular and morphological phylogenetic analyses. Mol. Biol. Evol. 34, 772-773 (2016).

96. Drummond, A. J., Suchard, M. A., Xie, D. \& Rambaut, A. Bayesian phylogenetics with BEAUti and the BEAST 1.7. Mol. Biol. Evol. https://doi.org/10.1093/molbev/mss075 (2012).

97. Bouckaert, R. et al. BEAST 2.5: An advanced software platform for Bayesian evolutionary analysis. PLoS Comput. Biol. https:// doi.org/10.1371/journal.pcbi.1006650 (2019).

98. Rambaut, A., Drummond, A. J., Xie, D., Baele, G. \& Suchard, M. A. Posterior summarization in Bayesian phylogenetics using tracer 1.7. Syst. Biol. 67, 901-904 (2018).

99. Rambaut, A. FigTree v1.4.3. Molecular evolution, phylogenetics and epidemiology (2016).

100. Radimilahy, C. Mahilaka: An Archaeological Investigation of an Early Town in Northwestern Madagascar (PhD Dissertation) (Acta Universitatis Upsaliensis, Uppsala, 1998).

101. Walsh, M. T. Island subsistence: Hunting, trapping and the translocation of wildlife in the Western Indian Ocean. Azania Archaeol. Res. Africa 42, 83-113 (2007).

102. Li, J. et al. Artificial selection of the melanocortin receptor 1 gene in Chinese domestic pigs during domestication. Heredity (Edinb). 105, 274-281 (2010).

103. Kijas, J. M. H. et al. Melanocortin receptor 1 (MC1R) mutations and coat color in pigs. Genetics 150, 1177-1185 (1998).

104. Arauco-Shapiro, G., Schumacher, K. I., Boersma, D. \& Bouzat, J. L. The role of demographic history and selection in shaping genetic diversity of the Galápagos penguin (Spheniscus mendiculus). PLoS ONE 15, 1-20 (2020).

105. Beck, H. E. et al. Present and future Köppen-Geiger climate classification maps at 1-km resolution. Sci. Data 5, 180214 (2018).

106. Froeschke, G. \& Sommer, S. MHC Class II DRB variability and parasite load in the striped mouse (Rhabdomys pumilio) in the Southern Kalahari. Mol. Biol. Evol. 22, 1254-1259 (2005).

107. Froeschke, G. \& Sommer, S. Insights into the complex associations between MHC Class II DRB polymorphism and multiple gastrointestinal parasite infestations in the striped mouse. PLoS ONE 7, e31820 (2012).

108. Yanagida, T. et al. Genetics of the pig tapeworm in Madagascar reveal a history of human dispersal and colonization. PLoS One 9, e109002 (2014).

109. Braae, U. C. et al. Taenia solium taeniosis/cysticercosis and the co-distribution with schistosomiasis in Africa. Parasites Vectors 8, 1-14 (2015).

110. Macpherson, C. N. L. \& Craig, P. S. Trichinella in Africa and the nelsoni affair. In Parasitic Helminths and Zoonoses in Africa (eds Macpherson, C. \& Craig, P.) 83-100 (Springer, Netherlands, 1991). https://doi.org/10.1007/978-94-011-3054-7 4.

111. Sarovich, D. S. et al. Phylogenomic analysis reveals an Asian origin for African Burkholderia pseudomallei and further supports Melioidosis Endemicity in Africa. mSphere 1, 1-12 (2016).

112. Kaesler, E. et al. Shared evolutionary origin of major histocompatibility complex polymorphism in sympatric lemurs. Mol. Ecol. 26, 5629-5645 (2017).

113. Kloch, A., Babik, W., Bajer, A., Siński, E. \& Radwan, J. Effects of an MHC-DRB genotype and allele number on the load of gut parasites in the bank vole Myodes glareolus. Mol. Ecol. 19(Suppl 1), 255-265 (2010).

114. Kusza, S. et al. Transcription specificity of the class Ib genes SLA-6, SLA-7 and SLA-8 of the swine major histocompatibility complex and comparison with class Ia genes. Anim. Genet. 42, 510-520 (2011).

115. Chardon, P. et al. Sequence of the swine major histocompatibility complex region containing all non-classical class I genes. Tissue Antigens 57, 55-65 (2001).

116. Le Gal, F. A. et al. HLA-G-mediated inhibition of antigen-specific cytotoxic T lymphocytes. Int. Immunol. 11, 1351-1356 (1999).

117. Fournel, S. et al. Cutting edge: Soluble HLA-G1 triggers CD95/CD95 ligand-mediated apoptosis in activated CD8 ${ }^{+}$cells by interacting with CD8. J. Immunol. 164, 6100-6104 (2000).

118. Hunt, J. S., Langat, D. K., McIntire, R. H. \& Morales, P. J. The role of HLA-G in human pregnancy. Reprod. Biol. Endocrinol. 4, $1-8(2006)$.

119. Minami, R. et al. BAG-6 is essential for selective elimination of defective proteasomal substrates. J. Cell Biol. 190, 637-650 (2010).

120. Jori, F. \& Bastos, A. D. S. Role of wild suids in the epidemiology of African swine fever. EcoHealth 6, 296-310 (2009).

121. Brown, V. R. \& Bevins, S. N. A Review of African Swine fever and the potential for introduction into the United States and the possibility of subsequent establishment in feral swine and native ticks. Front. Vet. Sci. 5, 1-18 (2018).

122. Fowler, M. E. Husbandry and diseases of captive wild swine and peccaries. Rev. Sci. Tech. 15, 141-154 (1996). 


\section{Acknowledgements}

The authors would like to thank the Directorate General of Water and Forests of Madagascar (Direction Générale des Eaux et Forêts de Madagascar) for permission to collect samples for this study. Thierry Caliman, Koos Steyn and Stewart Lowden provided several samples.

\section{Author contributions}

J.G. and C.L. designed the research. M.P., S.M.G., and P.J.T. provided and collected bushpig samples. C.L. and G.B. performed DNA extractions. C.L. analysed and interpreted the data, and wrote the manuscript. J.D. and M.J.H. assisted in analysis of the data and contributed to data interpretation. J.G., S.M.G., M.P., G.B., L.F., and P.J.T. contributed to the interpretation and revisions of the paper. All authors read and approved the final manuscript.

\section{Funding}

C.L., J.D. and J.G. acknowledge the funding support of the Sydney School of Veterinary Science, University of Sydney, to undertake this study. P.J.T. acknowledges the funding of the Department of Science and Technology (DST) and the National Research Foundation (NRF) through the South African Research Chairs initiative (SARChI) Chair on Biodiversity Value and Change, hosted at the University of Venda and co-hosted by the Cenre for Invasion Biology at University of Stellenbosch (NRF Grant number 87311). GB is supported by the LABEX TULIP (ANR-10-LABX-0041) and CEBA (ANR-10-LABX-25-01).

\section{Competing interests}

The authors declare no competing interests.

\section{Additional information}

Supplementary information is available for this paper at https://doi.org/10.1038/s41598-020-77279-5.

Correspondence and requests for materials should be addressed to J.G.

Reprints and permissions information is available at www.nature.com/reprints.

Publisher's note Springer Nature remains neutral with regard to jurisdictional claims in published maps and institutional affiliations.

(f) Open Access This article is licensed under a Creative Commons Attribution 4.0 International License, which permits use, sharing, adaptation, distribution and reproduction in any medium or format, as long as you give appropriate credit to the original author(s) and the source, provide a link to the Creative Commons licence, and indicate if changes were made. The images or other third party material in this article are included in the article's Creative Commons licence, unless indicated otherwise in a credit line to the material. If material is not included in the article's Creative Commons licence and your intended use is not permitted by statutory regulation or exceeds the permitted use, you will need to obtain permission directly from the copyright holder. To view a copy of this licence, visit http://creativecommons.org/licenses/by/4.0/.

(C) The Author(s) 2020 